Research Article

\title{
Recent Changes in the Annual Mean Regional Hadley Circulation and Their Impacts on South America
}

\author{
Ana Carolina Vasques Freitas and Tércio Ambrizzi \\ Institute of Astronomy, Geophysics and Atmospheric Sciences, 05508-090 São Paulo, SP, Brazil \\ Correspondence should be addressed to Ana Carolina Vasques Freitas; ana.vasques@gmail.com
}

Received 12 February 2015; Revised 16 April 2015; Accepted 23 April 2015

Academic Editor: Anthony R. Lupo

Copyright (C) 2015 A. C. V. Freitas and T. Ambrizzi. This is an open access article distributed under the Creative Commons Attribution License, which permits unrestricted use, distribution, and reproduction in any medium, provided the original work is properly cited.

\begin{abstract}
This work employs the regional climate model RegCM4 and observational datasets to investigate the impacts of changes in the intensity and poleward edge of regional HC over South America (HCSA) on the patterns of wind, geopotential height, precipitation, and temperature during the period 1996-2011. Significant trends of HCSA intensification and poleward expansion are found during the period analyzed. To evaluate the effects of these changes over SA, two composites, representing the intensification and poleward expansion cases, are examined separately. Significant correlations are seen between the temperature, zonal wind, and the HCSA intensity over the northern, central, and southern regions of SA and South Atlantic. Results show that, in both composites, regions with anomalous easterly (westerly) winds coming from (towards) the Atlantic Ocean have negative (positive) correlations with the HCSA intensity and poleward edge. The model performance varies regionally and the southern SA region exhibits better agreement with the observations. The role of the sea surface temperatures in driving the changes in the HCSA is examined. Notable similarity is found in the results for the two cases analyzed, which could indicate that, in most cases, the changes in the intensity and poleward edge of the HCSA are occurring simultaneously.
\end{abstract}

\section{Introduction}

The differential heating between the tropics-extratropics results in the formation of a meridional circulation, the Hadley circulation, with warmer air rising in the ascending branch over equatorial areas and colder air sinking over the subtropics in both the Southern and Northern Hemispheres [1]. This circulation is one of the fundamental regulators of the earth's energy budget, transporting heat poleward and, thus, reducing the resulting equator-to-pole temperature gradient.

There has been a recent and growing interest in studying the Hadley Cell (HC) changes in response to global climate change. Most studies have focused on the changes in HC strength and width, with the objective of verifying how these modifications affect the regional and global climates. Observations show that the $\mathrm{HC}$ has widened by about $2^{\circ}-5^{\circ}$ since 1979 and this observed widening cannot be explained by natural variability [2]. This widening and the concomitant poleward displacement of the subtropical dry zones may be accompanied by large-scale drying near $30^{\circ} \mathrm{N}$ and $30^{\circ} \mathrm{S}$. As well, idealized and comprehensive global circulation models have shown a widening of the $\mathrm{HC}$ in response to increases in greenhouse gases and changes in the thermal structure of the polar stratosphere $[3,4]$.

Quan et al. [5] found consistent evidence for an intensification of the Northern Hemisphere winter HC since 1950, as an atmospheric response to the observed tropical ocean warming trend, together with the intensification in El Niño's interannual fluctuations, including larger amplitude and increased frequency after 1976. However, a similar trend of an intensified southward overturning $\mathrm{HC}$ is not detected during the Southern Hemisphere winter. The authors stated that this can indicate that such an ocean-atmosphere feedback process has been much weaker or has not even existed over the South Pacific Ocean during the southern winter since 1950.

Most of the studies cited above are focused on the investigation of the changes in the zonal mean HC, whereas the modifications in the regional HCs are still lesser known. As land, sea, and topography are not evenly distributed, changes 
in the HC should be different in various regions [6]. Although the $\mathrm{HC}$ is referred to in some studies as a global symmetric zonally meridional circulation [7], it is possible to analyze its impact and variability in a regional level. However, it is good to highlight that, in this case, the atmospheric circulations may not be closed cells, in particular if we also consider the rotational component of wind [8].

Some studies have demonstrated that alterations in regional $\mathrm{HCs}$ could have an important influence on the anomalies of the regional climates. Ambrizzi et al. [9] analyzed the influence of the El Niño-Southern Oscillation (ENSO) events on the regional Hadley and Walker cells and their respective impacts on the South American seasonal rainfall. As not all ENSO events follow a canonical pattern, the authors demonstrated that, depending on the conditions of the Atlantic Sea Surface Temperature (SST) anomalies, the position of the Intertropical Convergence Zone (ITCZ) can be modified, the ascending and descending branches of the related regional $\mathrm{HC}$ may vary, and the South American rainy season may be strongly affected. Chen et al. [6] investigated long-term trends in the intensity and poleward edge of the regional HCs in six selected regions using six reanalyses, Outgoing Longwave Radiation (OLR), and precipitation datasets. In the Southern Hemisphere $(\mathrm{SH})$, the authors found a significant poleward expansion trend of the HC localized over the South America, with significant impact on precipitation anomalies in this region. The results found by the authors also indicated that the poleward expansion of the zonal mean HC, identified by several studies, could be attributed mainly to the poleward expansion of the regional $\mathrm{HC}$ over South America. Zeng et al. [10] demonstrated that changes in the HC intensity in the western and eastern Pacific are associated with anomalous East Asian winter monsoon. Thus, changes in regional HCs are of great importance for the regional climate variability [6].

In the present study, composite analyses are performed to examine the impact of the changes in intensity and poleward edge of the regional $\mathrm{HC}$ over South America on the patterns of wind, geopotential height, precipitation, and temperature during the 1996-2011 period. This is addressed using mainly the regional climate model version 4 (RegCM4) [11] and the Era-Interim reanalysis [12] of European Centre for Medium Range Forecasting (ECMWF).

The studies about regional HCs cited above used observational datasets. Thus, as far as we know, little attention has been paid to the investigation of the impacts of changes in regional HCs using regional climate modelling. It is important to assess the performance of the regional climate models in simulating local anomalies associated with changes in regional HCs. Local changes in temperature and precipitation could be quite different from the coarse-scale changes projected by global models. Thus, this assessment may prove very useful in the search to understand the future of these circulations in a changing climate and the local anomalies associated.

Details of the model and simulation are given in the Sections 2.1 and 2.2. In Section 2.3, we describe our methodology and show how we set up the composites that represent changes in the intensity and poleward edge of regional
HC over South America. We investigate the impacts of the regional HC intensification in Section 3, whereas, in Section 4, the impacts of the regional HC poleward expansion are examined. Finally, conclusions highlighting the main results of the paper are given in Section 5.

\section{Methodology}

2.1. RegCM4 Details. Giorgi et al. [11] described the RegCM4 model details, so we give only a brief overview here. RegCM4 is an evolution of its previous version, RegCM3, described by Pal et al. [13]. Thus, it is a hydrostatic, compressible, sigma$\mathrm{p}$ vertical coordinate model run on an Arakawa B-grid in which wind and thermodynamical variables are horizontally staggered. A time-splitting explicit integration scheme is used in which the two fastest gravity modes are first separated from the model solution and then integrated with smaller time steps. This allows the use of a longer time step for the rest of the model.

Radiative transfer calculations in RegCM4 are carried out with the radiative transfer scheme of the global model CCM3 [14]. This includes calculations for the short-wave and infrared parts of the spectrum, including both atmospheric gases and aerosols. The scheme includes contributions from all main greenhouse gases, that is, $\mathrm{H}_{2} \mathrm{O}, \mathrm{CO}_{2}, \mathrm{O}_{3}, \mathrm{CH}_{4}, \mathrm{~N}_{2} \mathrm{O}$, and CFCs, and solar radiative processes are treated using a delta-Eddington formulation. Scattering and absorption of solar radiation by aerosols are also included based on the aerosol optical properties (absorption coefficient and single scattering albedo).

Land surface processes are described via the BiosphereAtmosphere Transfer Scheme (BATS) of Dickinson et al. [15]. This scheme, which has been used for many years, includes a 1-layer vegetation module, a 1-layer snow module, a forcerestore model for soil temperatures, a 3-layer soil scheme, and a simple surface runoff parameterization. The scheme includes twenty surface types and twelve soil color and soil texture types.

RegCM4 includes three options for representing cumulus convection. The first is a simplified version of the Kuo-type scheme of Anthes [16], as described by Anthes et al. [17], the second is that of Grell [18] in the implementation of Giorgi et al. [19], and, the third, which is the so-called Massachusetts Institute of Technology (MIT) scheme [20], is introduced in the RegCM3 by Pal et al. [13].

2.2. Simulation Details and Observed Data. The daily data with 6-hourly temporal resolution used to run the model are obtained from the RegCM4 data website (http://users.ictp.it/ $\sim$ pubregcm/RegCM4/globedat.htm). The model version used here is the 4.3.5.7. The lateral meteorological boundary conditions are provided by the Era-Interim reanalysis of ECMWF [12]. The Weekly Optimum Interpolation Sea Surface Temperature (OI_WK) version 2 [21] of National Oceanic and Atmospheric Administration (NOAA), which is available weekly on a $1.0^{\circ} \times 1.0^{\circ}$ grid, is used to force the model. Table 1 shows the technical details of the simulation performed 
TABLE 1: Technical details of the simulation performed.

\begin{tabular}{|c|c|}
\hline \multicolumn{2}{|l|}{ Simulation parameters } \\
\hline $\begin{array}{l}\text { Domain cartographic projection } \\
\text { (iproj) }\end{array}$ & $\begin{array}{l}\text { Rotated Mercator } \\
\text { (ROTMER) }\end{array}$ \\
\hline $\begin{array}{l}\text { Grid point horizontal resolution in } \\
\mathrm{km}(\mathrm{ds})\end{array}$ & $60.0 \mathrm{~km}$ \\
\hline $\begin{array}{l}\text { Number of points in the N/S } \\
\text { direction (iy) }\end{array}$ & 152 \\
\hline $\begin{array}{l}\text { Number of points in the E/W } \\
\text { direction (jx) }\end{array}$ & 192 \\
\hline Number of vertical levels (kz) & 18 \\
\hline $\begin{array}{l}\text { Central latitude of model domain in } \\
\text { degrees (clat) }\end{array}$ & -23.00 \\
\hline $\begin{array}{l}\text { Central longitude of model domain } \\
\text { in degrees (clon) }\end{array}$ & -33.00 \\
\hline Cumulus convection scheme (icup) & 1-Kuo \\
\hline Moisture scheme (ipptls) & $\begin{array}{l}\text { 1-Explicit moisture } \\
\text { (SUBEX; Pal et al. [42]) }\end{array}$ \\
\hline $\begin{array}{l}\text { Lateral boundary conditions } \\
\text { scheme (iboudy) }\end{array}$ & $\begin{array}{l}\text { 5-Relaxation, } \\
\text { exponential technique }\end{array}$ \\
\hline Boundary layer scheme (ibltyp) & 1-Holtslag PBL [43] \\
\hline Ocean flux scheme (iocnflx) & 2-Zeng et al. [44] \\
\hline
\end{tabular}

including the simulation domain. The model is run for the period 1995-2011. The first year is discarded to avoid problems related to the spin-up.

The Kuo-type cumulus parameterization is used here. In this scheme, convection is triggered in a convectively unstable low troposphere when the column moisture convergence exceeds a threshold value [11]. Some studies found that the Kuo scheme produces satisfactory seasonal and annual precipitation $[22,23]$. We will show that this scheme could reasonably reproduce the precipitation anomalies, especially in the southern region, associated with the modifications in the HC over South America.

The Era-Interim monthly data, the Global Precipitation Climatology Centre dataset (GPCC) (GPCC dataset is available on http://www.esrl.noaa.gov/psd/data/gridded/data.gpcc .html) [24], and the SST monthly mean data of the Hadley Centre Global Sea Ice and Sea Surface Temperature (HADISST) (HADISST dataset is available on http://www.metoffice .gov.uk/hadobs/hadisst/data/download.html) [25] are used for validation of the model results.

2.3. Methods. Horizontal wind field can be expressed by the sum of a nondivergent (or rotational) component and a divergent (or irrotational) component [26, 27]:

$$
\vec{v}=\vec{v}_{\psi}+\vec{v}_{\chi}=\vec{k} \times \nabla \psi+\nabla \chi,
$$

where $\psi$ is stream function and $\chi$ is velocity potential. The divergent component is fundamental to study the atmospheric divergence-convergence that drives the vertical motion and circulation in the tropics [28].
The methodology used here to define the intensity index and poleward edge of the regional $\mathrm{HC}$ is similar to Chen et al. [6]. The regional HC intensity is defined through an index based on the vertical shear of divergent meridional winds at $200 \mathrm{hPa}$ and $850 \mathrm{hPa}$, whereas the poleward edge of the regional $\mathrm{HC}$ is identified as the latitude where the OLR is equal to $240 \mathrm{~W} \mathrm{~m}^{-2}$ (found through linear interpolation). The OLR data is obtained from the Climate Diagnostics Center of the National Oceanic and Atmospheric Administration (NOAA-CDC) (OLR data is available on http://www .esrl.noaa.gov/psd/data/gridded/data.interp_OLR.html) in a $2.5^{\circ} \times 2.5^{\circ}$ grid [29]. Annual means are constructed by averaging the monthly data from January to December.

Initially, two domains are selected for the regional HCs: the South America $\left(80^{\circ} \mathrm{W}-45^{\circ} \mathrm{W}\right)$ and Atlantic Ocean $\left(38^{\circ} \mathrm{W}-\right.$ $\left.10^{\circ} \mathrm{E}\right)$ regions. The regional HCs in these locations can have an important influence on synoptic weather and climate systems [6]. The annual mean of the intensity index for the regional HC over South America (hereafter denoted as HCSA) is defined as the difference in the area-averaged $\left(80^{\circ} \mathrm{W}-45^{\circ} \mathrm{W}\right.$, $20^{\circ} \mathrm{S}-0$ ) divergent meridional winds between $200 \mathrm{hPa}$ and $850 \mathrm{hPa}$. This latitudinal band is chosen according to the climatological distributions of divergent winds (Figure 1(a)). Definition of the intensity index for the regional HC over Atlantic Ocean (hereafter denoted HCAO) is similar to those of the HCSA, except that the divergent meridional winds are averaged over $38^{\circ} \mathrm{W}-10^{\circ} \mathrm{E}, 5^{\circ} \mathrm{N}-20^{\circ} \mathrm{S}$ (Figure 1(b)). Chen et al. [6] conducted a series of tests and found that the result does not change much if other latitudinal bands are used.

The normalized time series for the annual mean HCSA intensity index (Figure 2(a)) presents a significant negative trend $\left(-0.12\right.$ year $\left.^{-1}\right)$. This indicates an intensification of the $\mathrm{HCSA}$, as the $\mathrm{HC}$ in $\mathrm{SH}$ is negative corresponding to a counterclockwise circulation. Thus, cases of strong HCSA are selected based on the years that present HCSA normalized intensity index equal to or less than -1 in the period 19962011. The HCSA strong cases are 2005, 2008, 2010, and 2011. Figure 3(a) shows the HCSA anomaly for these strong cases. It is possible to note an intense ascending branch from 0 to $5^{\circ} \mathrm{N}$ and a descending branch around $30^{\circ} \mathrm{S}$.

It is worth highlighting that we are using the Era-Interim reanalysis data to calculate the intensity index. This dataset is chosen since it is the latest global atmospheric reanalysis produced by ECMWF and, thus, incorporates many important model improvements such as resolution and physics changes, the use of four-dimensional variational data assimilation, and various other changes in the analysis methodology [30]. Several studies found that Era-Interim has the best performance among reanalysis datasets [31,32]. Also, some studies found that the performance skills of the RegCM driven by EraInterim are better than by other reanalyses $[33,34]$.

As mentioned earlier, the HCSA poleward edge is defined by the latitude where the OLR annual mean is equal to $240 \mathrm{~W} \mathrm{~m}^{-2}$. Slight deviations from this OLR value, such as 236 or $245 \mathrm{~W} \mathrm{~m}^{-2}$, lead to similar results. Thus, a linear interpolation of the OLR annual mean values, averaged over $80^{\circ} \mathrm{W}-45^{\circ} \mathrm{W}$, was performed to obtain the latitude that defines 


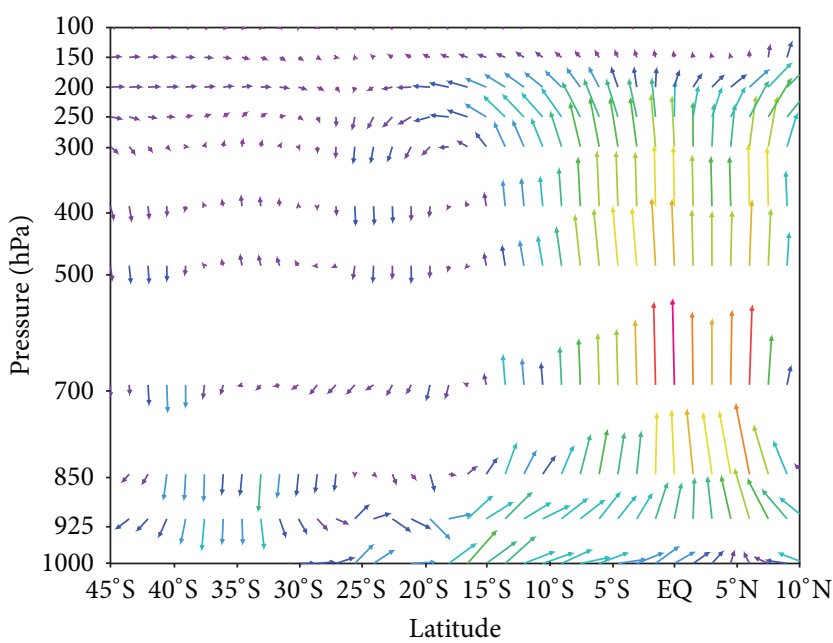

$\longrightarrow 2$

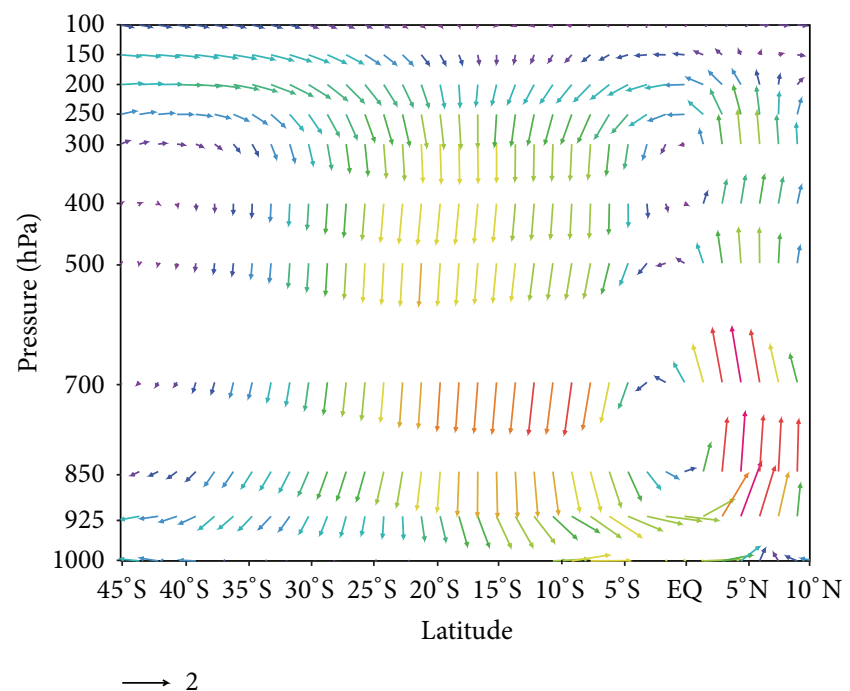

(b)

Figure 1: Annual mean of the regional HC in the period 1996-2011 over (a) South America averaged between $80^{\circ} \mathrm{W}$ and $45^{\circ} \mathrm{W}$ (HCSA) and (b) Atlantic Ocean averaged between $38^{\circ} \mathrm{W}$ and $10^{\circ} \mathrm{E}(\mathrm{HCAO})$. Vertical circulations are described by the vertical velocities (Pa s ${ }^{-1}$ ) and the divergent meridional winds $\left(\mathrm{m} \mathrm{s}^{-1}\right)$ based on the Era-Interim reanalysis. The vertical velocity has been multiplied by -100 . The color scale represents the vector's magnitude.

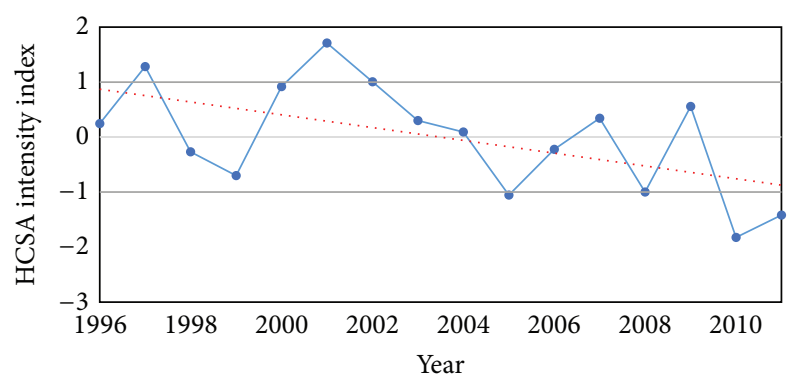

(a)

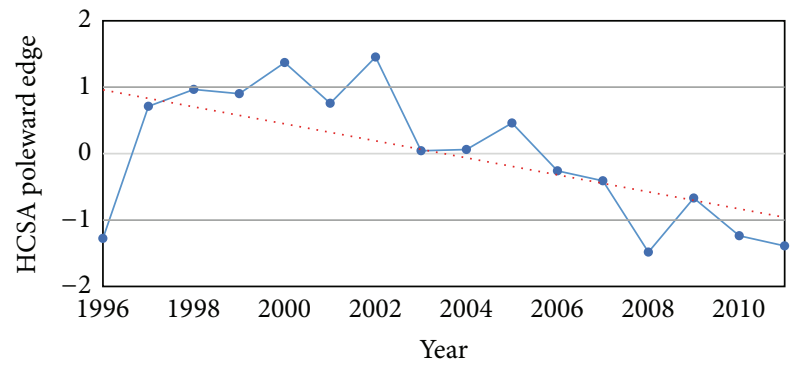

(b)

FIGURE 2: Normalized time series for the annual mean HCSA: (a) intensity index and (b) poleward edge in the period 1996-2011 with the linear trend (red dotted line).

the HCSA poleward edge. The normalized time series of the annual mean HCSA poleward edge (Figure 2(b)) presents a significant negative trend $\left(-0.13\right.$ degrees of latitude year $\left.{ }^{-1}\right)$, which indicates a poleward expansion of the HCSA. Thus, cases of HCSA poleward expansion are selected based on the years that present HCSA normalized poleward edge equal to or less than -1 in the period 1996-2011. The HCSA poleward expansion cases are 1996, 2008, 2010, and 2011. Interestingly, these three last years are also part of the HCSA strong cases. Figure 3(b) shows the HCSA anomaly for these poleward expansion cases. It is possible to note an ascending branch from 0 to $5^{\circ} \mathrm{N}$ and a descending branch around $35^{\circ} \mathrm{S}$. Here, as expected, the descending branch is stronger and is shifted towards the pole (Figure 3(b)) compared to the HCSA strong cases (Figure 3(a)). However, the ascending branch is weaker (Figure 3(b)) than for the HCSA strong cases (Figure 3(a)). Therefore, an intense upward motion, which induces more divergence in the upper troposphere, distinguishes a HCSA strong case, whereas a HCSA poleward expansion case is characterized by a strong and poleward shifted descending branch.

The normalized time series for the annual mean HCAO intensity index also shows a significant negative trend $(-0.13$ year $^{-1}$ ) (Figure 4(a)), but only the years 2008 and 2010 presented HCAO normalized intensity index equal to or less than -1 in the period 1996-2011. Moreover, the observed trend for the annual mean HCAO poleward edge normalized time series $\left(-0.11\right.$ year $^{-1}, p$ value $\left.=0.04\right)($ Figure $4(\mathrm{~b}))$ is not as significant as the HCSA poleward edge trend $\left(-0.13\right.$ year $^{-1}$, $p$ value $=0.01$ ). Therefore, we will focus on the impacts of the HCSA intensification and poleward expansion on the horizontal wind, precipitation, temperature, and geopotential height fields over South America. However, this investigation also encompasses the Ocean Atlantic region. 


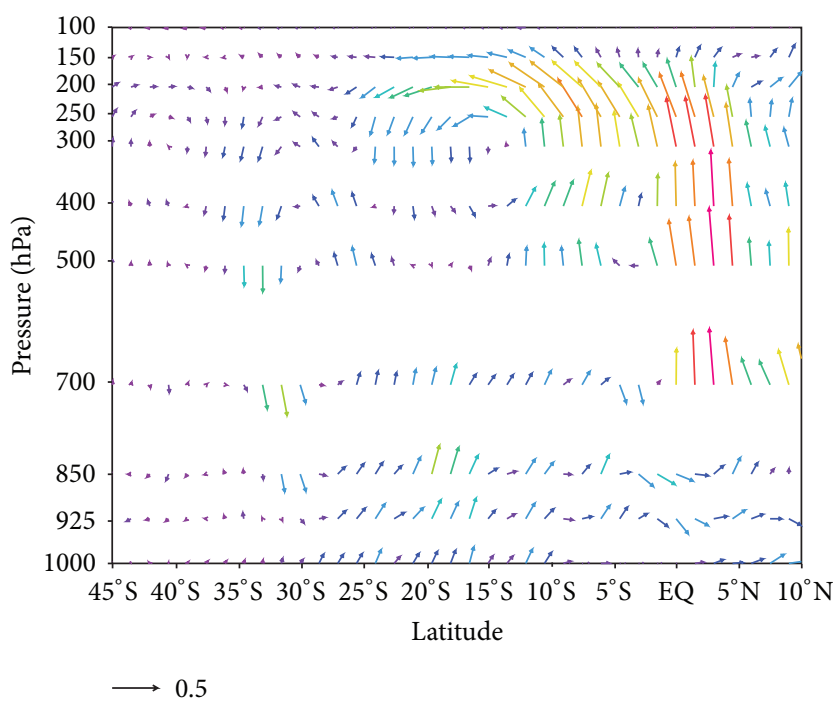

(a)

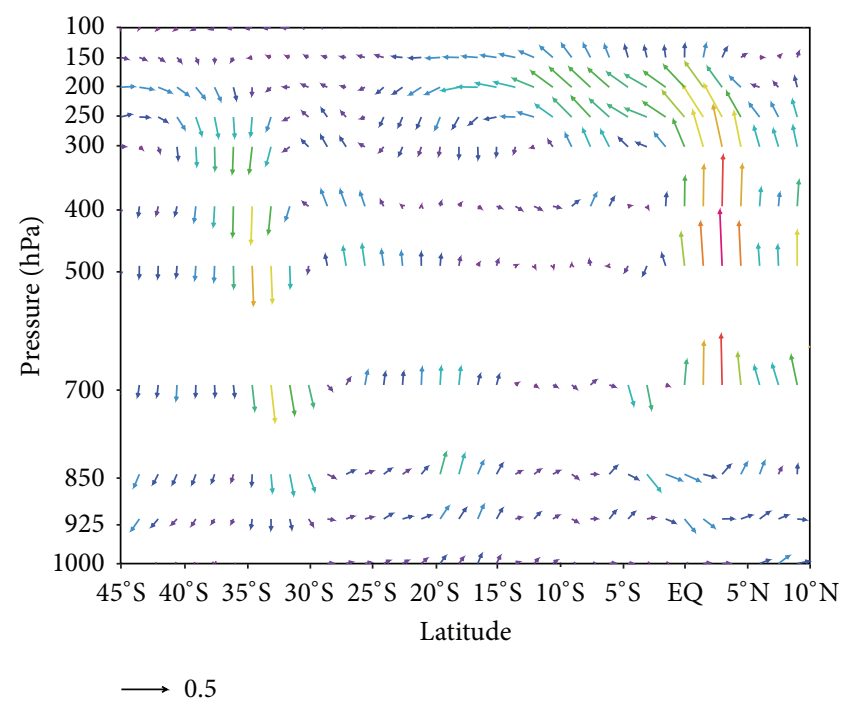

(b)

Figure 3: Annual mean of the HCSA anomaly based on the Era-Interim reanalysis for (a) strong cases and (b) poleward expansion cases. The vertical velocity has been multiplied by -100 . The color scale represents the vector's magnitude.

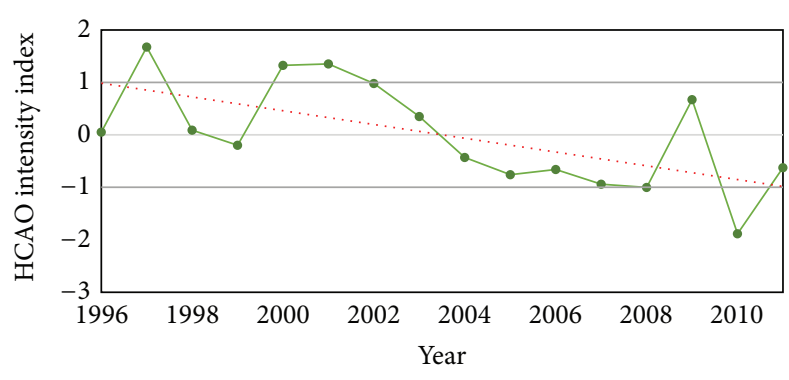

(a)

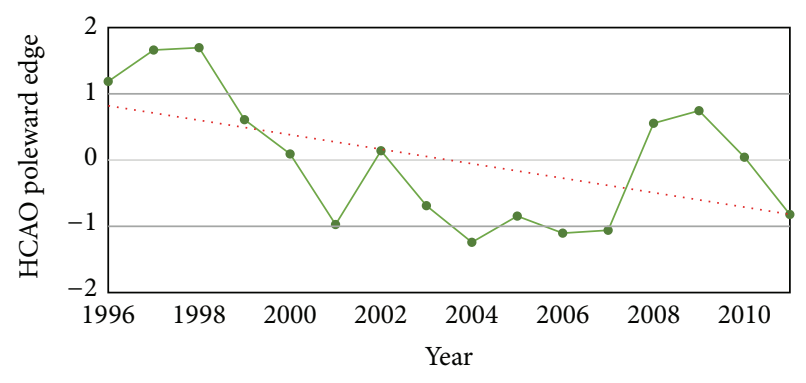

(b)

FIGURE 4: Normalized time series for the annual mean HCAO: (a) intensity index and (b) poleward edge in the period 1996-2011 with the linear trend (red dotted line).

The performance of the regional climate models varies greatly depending on the combination of physical parameterization schemes, simulation region, boundary conditions, and the horizontal resolution $[18,20]$. The skill of the RegCM4 over different regions covering the South America and Atlantic Ocean (Figure 5), during the 1996-2011 period, is evaluated quantitatively by analyzing the root mean square error (RMSE), bias, and spatial correlation coefficient of the simulation in relation to observations for the annual mean anomalies. We selected the regions in which the impacts of the HCSA intensification and poleward expansion are more prominent. The RMSE measures the overall magnitude of deviations regardless of their individual signs, while the bias measures systematic or predominant deviations in given directions [35]. The closer the values of RMSE and bias get to zero, the better the agreement between observed and simulated data is. The RMSE is calculated according to (2), where $x^{\prime M}$ and $x^{\prime O}$ are the anomalies of the model and the observations, respectively. The summation is carried out over
$N$ grid points in a predefined region. The bias and the spatial correlation coefficient are calculated according to (3) and (4), respectively. Consider

$$
\begin{aligned}
\text { RMSE } & =\sqrt{\frac{1}{N} \sum_{i=1}^{N}\left(x_{i}^{\prime M}-x_{i}^{\prime O}\right)^{2}} \\
\text { bias } & =\frac{1}{N} \sum_{i=1}^{N}\left(x_{i}^{\prime M}-x_{i}^{\prime O}\right) \\
\rho & =\frac{\sum_{i=1}^{N}\left(x_{i}^{\prime M}-\overline{x^{\prime M}}\right)\left(x_{i}^{\prime O}-\overline{x^{\prime O}}\right)}{\sqrt{\sum_{i=1}^{N}\left(x_{i}^{\prime M}-\overline{x^{\prime M}}\right)^{2}} \sqrt{\sum_{i=1}^{N}\left(x_{i}^{\prime O}-\overline{x^{\prime O}}\right)^{2}}} .
\end{aligned}
$$

\section{Impacts of the HCSA Intensification}

The vertical velocity and the divergent winds are the main fields analyzed when the regional $\mathrm{HC}$ is studied. However, 
TABLE 2: Area averaged root mean square error (RMSE) and bias and spatial correlation coefficient (CC) for the zonal wind ( $\mathrm{m} \mathrm{s}^{-1}$ ) at $200 \mathrm{hPa}$ (ZW200) and $850 \mathrm{hPa}(\mathrm{ZW} 850)$, geopotential height $(\mathrm{m})$ at $500 \mathrm{hPa}(\mathrm{GH})$, and air temperature (K) at $925 \mathrm{hPa}(\mathrm{AT})$ anomalies for HCSA strong cases over the first four regions of Figure 5.

\begin{tabular}{lccccccccccccc}
\hline \multirow{2}{*}{ Region } & \multicolumn{9}{c}{ RMSE } & \multicolumn{9}{c}{ BIAS } & \multicolumn{4}{c}{ CC } \\
& ZW200 & ZW850 & GH & AT & ZW200 & ZW850 & GH & AT & ZW200 & ZW850 & GH & AT \\
\hline 1 & 0.42 & 0.31 & 1.52 & 0.26 & 0.12 & 0.12 & 0.52 & -0.10 & 0.78 & 0.35 & -0.15 & 0.11 \\
2 & 0.91 & 0.18 & 3.29 & 0.23 & -0.67 & 0.02 & 3.18 & 0.04 & 0.68 & 0.50 & 0.87 & 0.40 \\
3 & 0.51 & 0.19 & 1.67 & 0.11 & 0.39 & 0.13 & 1.55 & 0.06 & 0.83 & 0.88 & 0.98 & 0.85 \\
4 & 0.65 & 0.25 & 3.13 & 0.19 & -0.11 & 0.11 & 2.25 & -0.01 & 0.84 & 0.73 & 0.91 & 0.55 \\
\hline
\end{tabular}

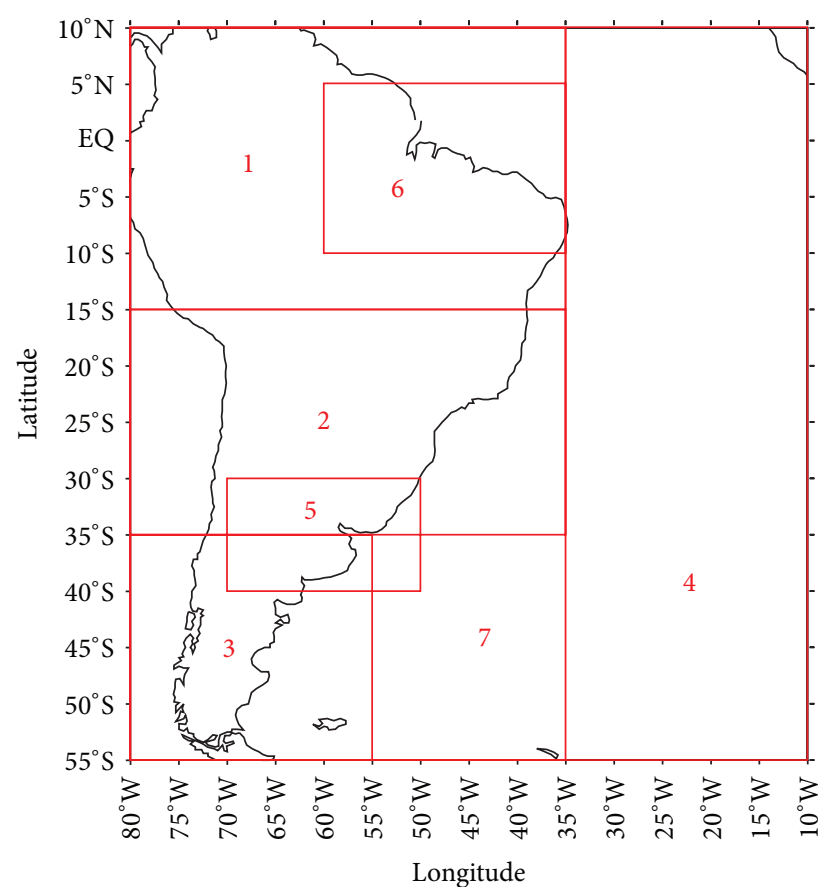

FIgURE 5: South America regions selected for statistical evaluation of model performance: (1) northern $\left(80^{\circ} \mathrm{W}-35^{\circ} \mathrm{W}: 15^{\circ} \mathrm{S}-10^{\circ} \mathrm{N}\right)$, (2) central $\left(80^{\circ} \mathrm{W}-35^{\circ} \mathrm{W}: 35^{\circ} \mathrm{S}-15^{\circ} \mathrm{S}\right)$, (3) southern $\left(80^{\circ} \mathrm{W}-55^{\circ} \mathrm{W}: 55^{\circ} \mathrm{S}-\right.$ $\left.35^{\circ} \mathrm{S}\right)$, (4) entire domain $\left(80^{\circ} \mathrm{W}-10^{\circ} \mathrm{W}: 55^{\circ} \mathrm{S}-10^{\circ} \mathrm{N}\right)$, (5) southeast $\left(70^{\circ} \mathrm{W}-50^{\circ} \mathrm{W}: 40^{\circ} \mathrm{S}-30^{\circ} \mathrm{S}\right)$, (6) northeast $\left(60^{\circ} \mathrm{W}-35^{\circ} \mathrm{W}: 10^{\circ} \mathrm{S}-5^{\circ} \mathrm{N}\right)$, and (7) all South America $\left(80^{\circ} \mathrm{W}-35^{\circ} \mathrm{W}: 55^{\circ} \mathrm{S}-10^{\circ} \mathrm{S}\right)$.

there is a remarkable impact of the changes in the $\mathrm{HC}$ on the horizontal winds at low and high troposphere, as they are linked to the vertical movement of the air. Indeed, the trade winds are the expression of the $\mathrm{HC}$ at surface.

Figure 6 shows the anomalies of the annual mean horizontal wind at 200 and $850 \mathrm{hPa}$ for the HCSA strong cases based on the Era-Interim reanalysis and the model simulation. Strong anomalous easterly winds coming from the Atlantic Ocean are seen over the northern South America (SA) at $200 \mathrm{hPa}$ in the reanalysis (Figure 6(a)) and, especially, in model simulation (Figure 6(c)), which exhibits a positive bias (0.12) for the zonal wind in this region (Table 2$)$. When entering the mainland, these winds rotate counterclockwise. Strong anomalous easterly winds coming from the Atlantic also hits the southeast of the continent and, then, they rotate clockwise, resulting in an anomalous trough, which is seen at $200 \mathrm{hPa}$ (Figure not shown) and $500 \mathrm{hPa}$ (Figure 7). The anomalous wind pattern at $850 \mathrm{hPa}$ is characterized by the strengthening of the trade winds around the equator, which spin in northeast direction before entering the northern SA, and by a counterclockwise circulation in the South Atlantic around $50^{\circ} \mathrm{S}$ in the reanalysis (Figure $6(\mathrm{~b})$ ) and model simulation (Figure 6(d)). This counterclockwise circulation results in a significant anomalous ridge, which is seen at $850 \mathrm{hPa}$ (Figure not shown) and $500 \mathrm{hPa}$ in the reanalysis and model simulation (Figure 7).

To investigate the quantitative link between the HCSA intensity and the annual changes in the zonal wind (stronger component of the horizontal wind), correlation coefficients between the HCSA annual intensity index and the annual mean zonal wind at 200 and $850 \mathrm{hPa}$ are displayed in Figure 8. The model simulation (Figure $8(\mathrm{c})$ ) is able to reproduce the signs (positives and negatives) of the correlation coefficients observed in the reanalysis (Figure 8(a)). Three regions with significant correlations (above 0.5 ) in the high troposphere are seen in the reanalysis (Figure 8(a)). Figures 6(a) and 6(c) showed that, for HCSA strong cases, the zonal component of the anomalous wind at $200 \mathrm{hPa}$ is easterly (negative) in the northern and southern SA regions, whereas in the central area of SA it is westerly (positive). In another way, Figures 8(a) and 8 (c) show that the anomalous easterly (westerly) winds coming from (towards) the Atlantic presents negative (positive) correlations with the HCSA intensity. At $850 \mathrm{hPa}$, significant positive correlations are seen in the reanalysis on the edge of northwest SA and negative correlations on the central-south area of the continent (Figure $8(\mathrm{~b})$ ). The model simulation shows significant positive correlations on a great part of the northwest SA (Figure 8(d)), probably due to the misrepresentation of the horizontal wind in this region (Figure 6(d)). At $850 \mathrm{hPa}$, it can also be seen that regions with anomalous easterly (westerly) winds coming from (towards) the Atlantic Ocean have negative (positive) correlations with the HCSA intensity.

The three regions (northern, central, and southern) with significant correlations seen in Figure 8(a), and the entire domain considered in the composite analyses, were selected for evaluation of model performance in reproducing the anomalies of zonal wind, geopotential height, and temperature (Figure 5). Table 2 shows that, for the annual mean zonal wind anomalies at $200 \mathrm{hPa}$, lower values of RMSE and bias (absolute value) and higher values of spatial correlation 


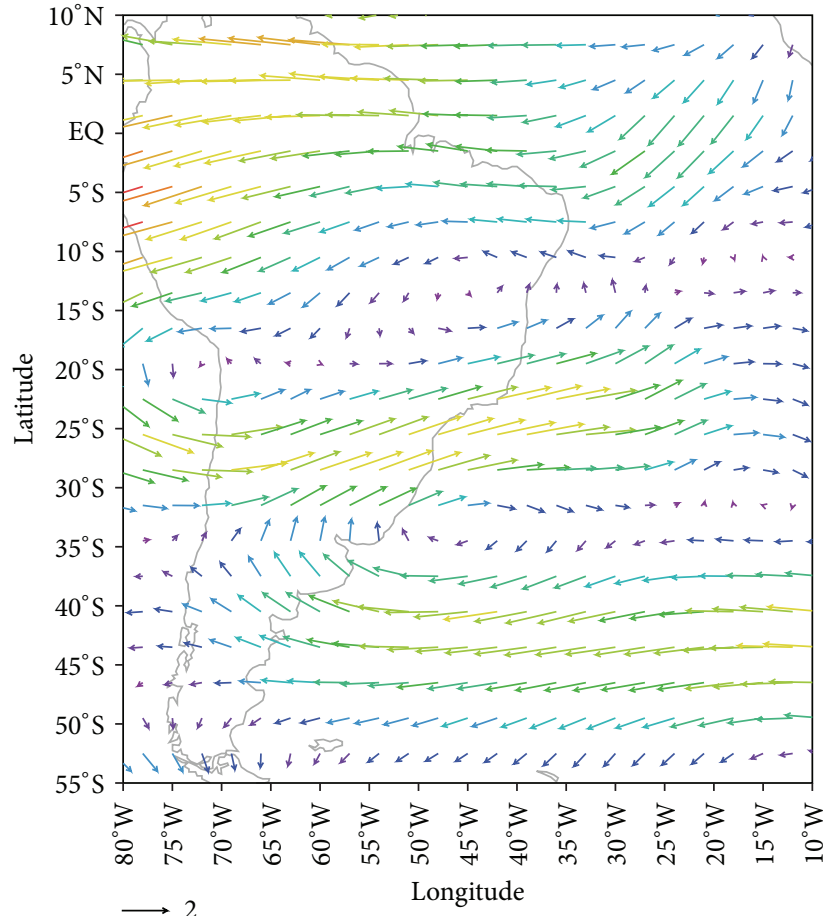

(a)

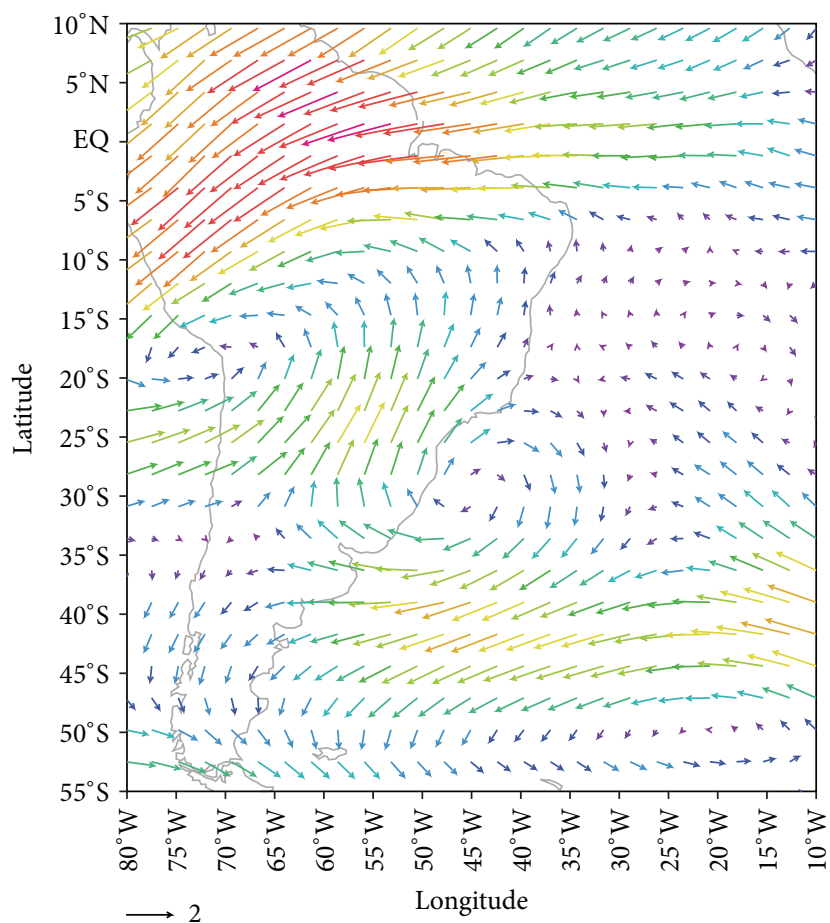

(c)

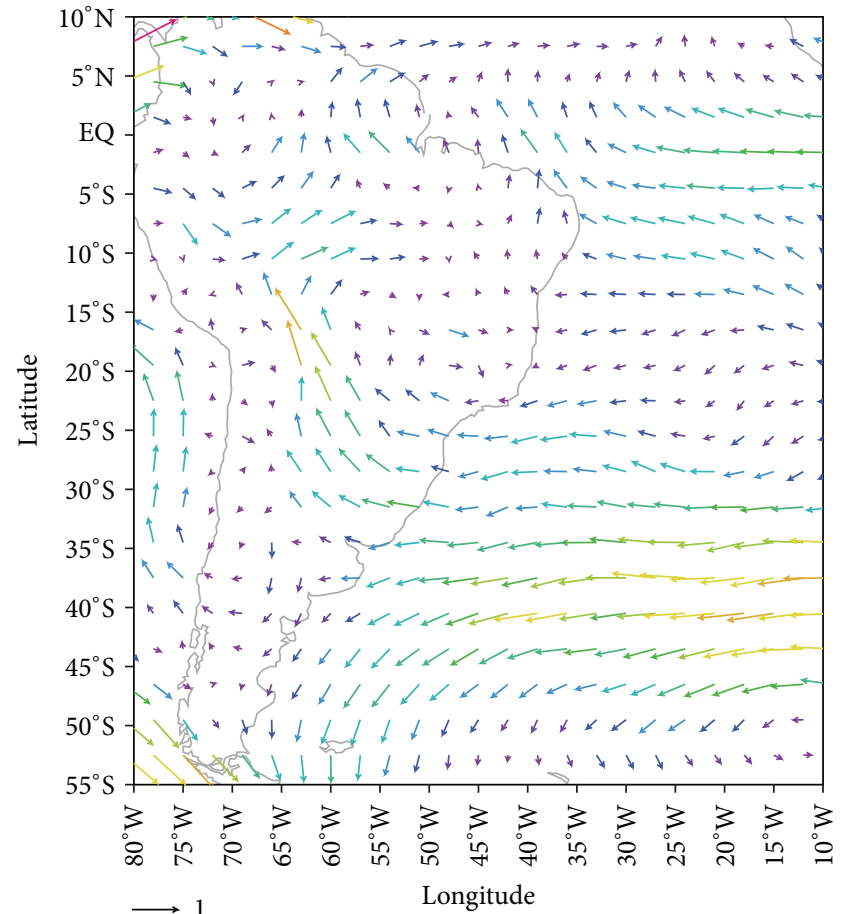

(b)

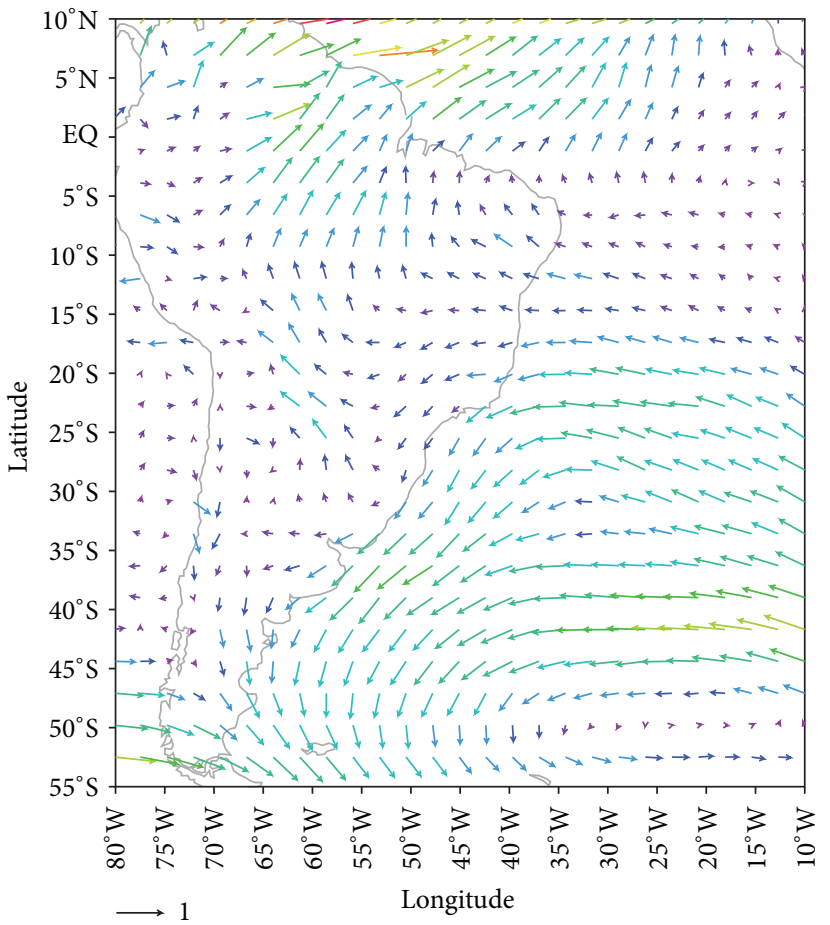

(d)

FIGURE 6: Annual mean horizontal wind $\left(\mathrm{m} \mathrm{s}^{-1}\right)$ anomaly for HCSA strong cases in the period 1996-2011 based on the Era-Interim reanalysis at (a) $200 \mathrm{hPa}$ and (b) $850 \mathrm{hPa}$ and RegCM4 simulation at (c) $200 \mathrm{hPa}$ and (d) $850 \mathrm{hPa}$. The color scale represents the vector's magnitude. 


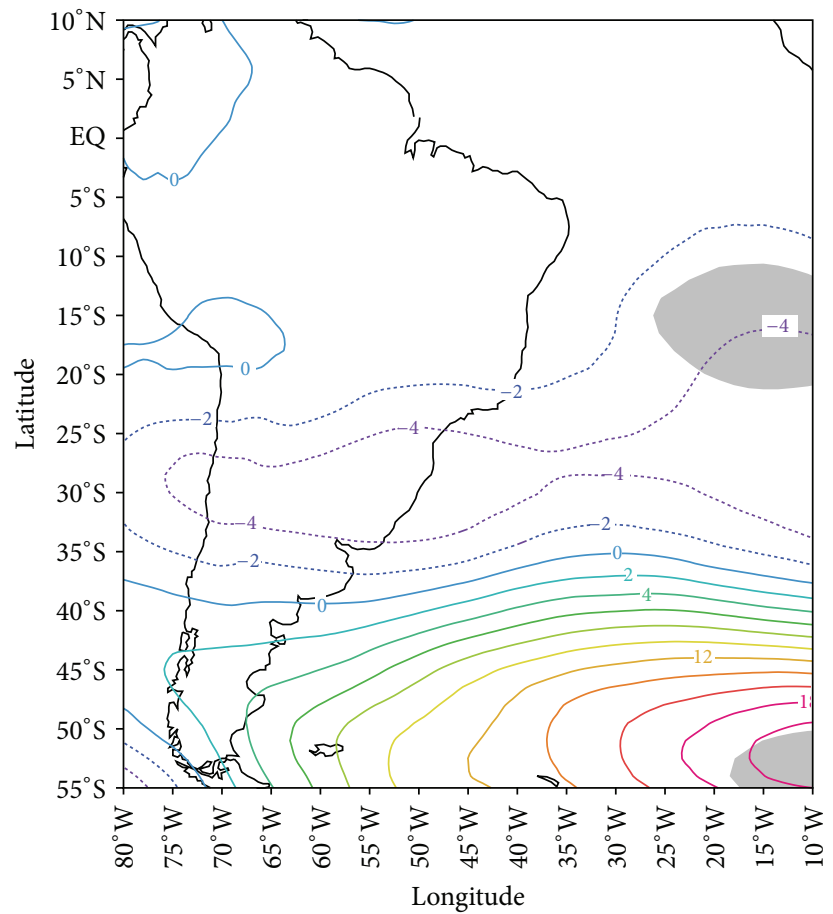

(a)

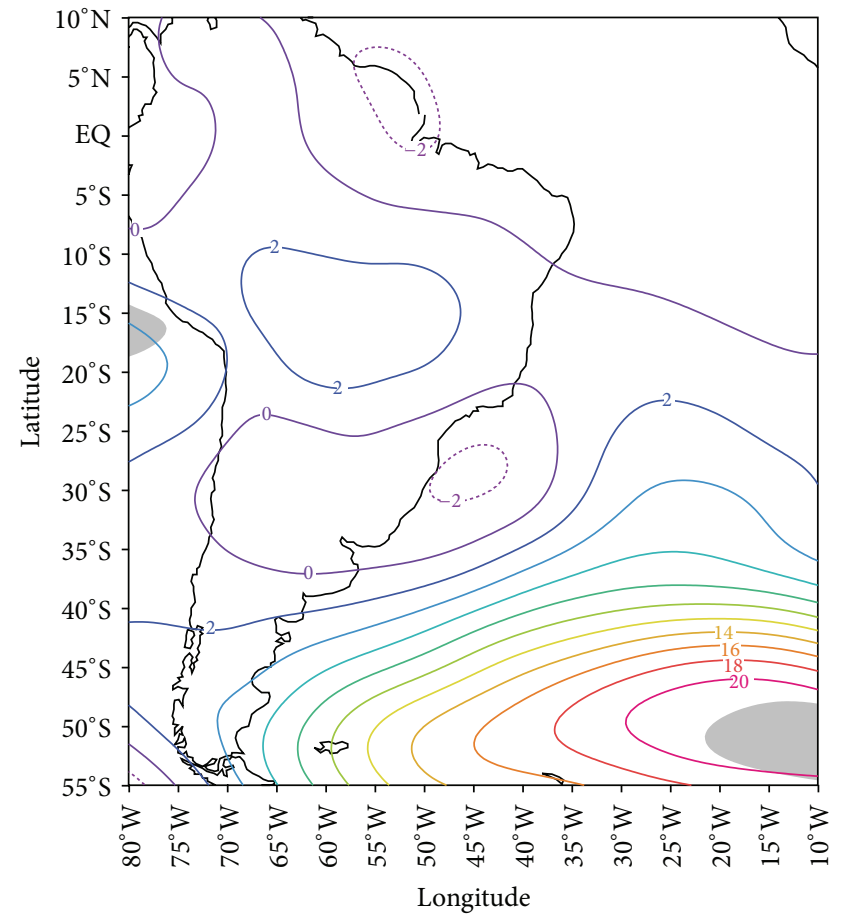

(b)

FIGURE 7: Annual mean geopotential height (m) anomaly for HCSA strong cases at $500 \mathrm{hPa}$ in the period 1996-2011 based on the (a) EraInterim reanalysis and (b) RegCM4 simulation. Contour intervals are $2 \mathrm{~m}$ and significant values above $90 \%$ confidence level from two-tailed Student's $t$-test are shaded.

are found mainly in the northern and southern SA and when we consider the entire domain (region 4 of Figure 5). Thus, at $200 \mathrm{hPa}$, the central region of SA exhibits weaker agreement between the model and observation for the zonal wind anomalies. Table 2 shows that the model underestimates the zonal wind anomalies in this region (bias $=-0.67)$. As well, Figures 6(c) and 7(b) show that the model simulates a strong anticyclonic anomalous circulation in the centralwestern region. Interestingly, at $850 \mathrm{hPa}$, the central region of SA exhibits the lowest value of RMSE and bias (0.18 and 0.02, resp.), but the spatial correlation is only 0.5 . Mid- and uppertropospheric winds influence low-level circulations; thus, the biases in low and high levels are somewhat connected. Increasing resolution can improve the results in the central region of SA, due to better representation of orography in this region in a high-resolution simulation. The highest spatial correlation for the zonal wind anomalies at $850 \mathrm{hPa}$ is found in the southern SA (0.88). The geopotential height is the variable that exhibits the highest values of RMSE and bias (mostly greater than 1) for all regions (Table 2). The lower values of RMSE and bias are found in the northern and southern SA, but the spatial correlation is weaker in the northern and stronger in the southern.

Figure 9 shows the annual mean temperature anomalies for HCSA strong cases. The reanalysis data presents significant positive anomalies on a great part of northern SA and equatorial Atlantic, whereas the negative anomalies are found over the east Pacific around $20^{\circ} \mathrm{S}$ (Figure 9(a)). The model shows significant positive anomalies only over the northeast edge of SA and over the equatorial Atlantic (Figure 9(b)). Indeed, the model underestimates the temperature anomalies in the northern region, as indicated by the bias value in this region (-0.11, Table 2). A positive (negative) bias in surface air temperature is associated with a negative (positive) bias in precipitation, as an underestimation (overestimation) of precipitation is usually associated with an underestimation (overestimation) of clouds, which enhances (reduces) the net short-wave radiation budget at surface, and consequently enhances (reduces) the net energy budget at surface [36]. Indeed, the model exhibits a positive bias (0.19) for the precipitation anomalies in the northern region. The lowest (highest) value of the RMSE (correlation) for the annual mean temperature anomalies is found in the southern region, indicating a good agreement between the model and observation.

Figure 10 displays the correlation between the HCSA annual intensity index and the annual mean temperature in the period 1996-2011. As in Figure 8(a), three significant regions (northern, central, and southern SA) are seen. However, the signs of the correlation coefficients in these three regions of Figure 10 are opposite in relation to Figure 8. Thus, positive (negative) correlations of the annual mean temperature (zonal wind) with the HCSA intensity are seen over the northern and southern SA in the 1996-2011 period. The opposite signal between the annual mean temperature and the zonal wind is also seen over the central regions of 


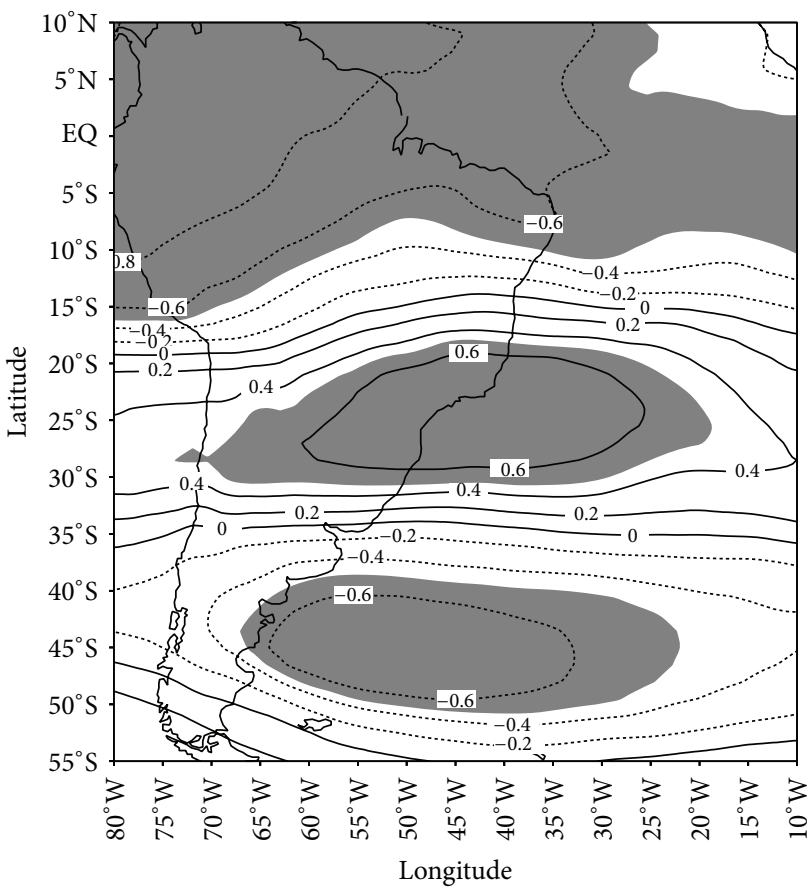

(a)

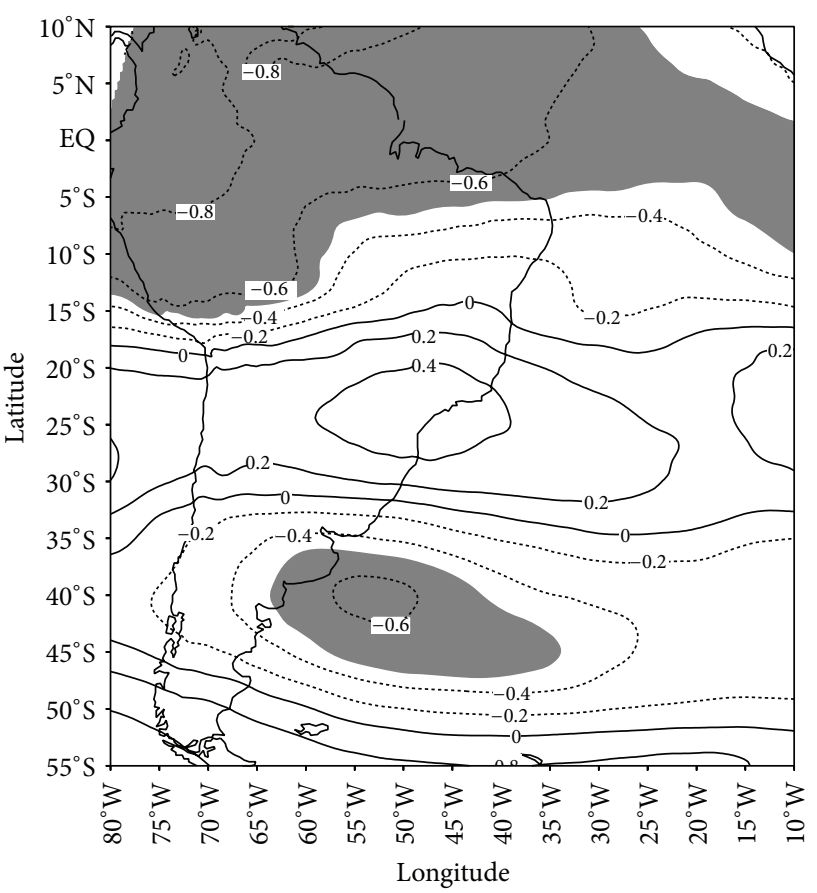

(c)

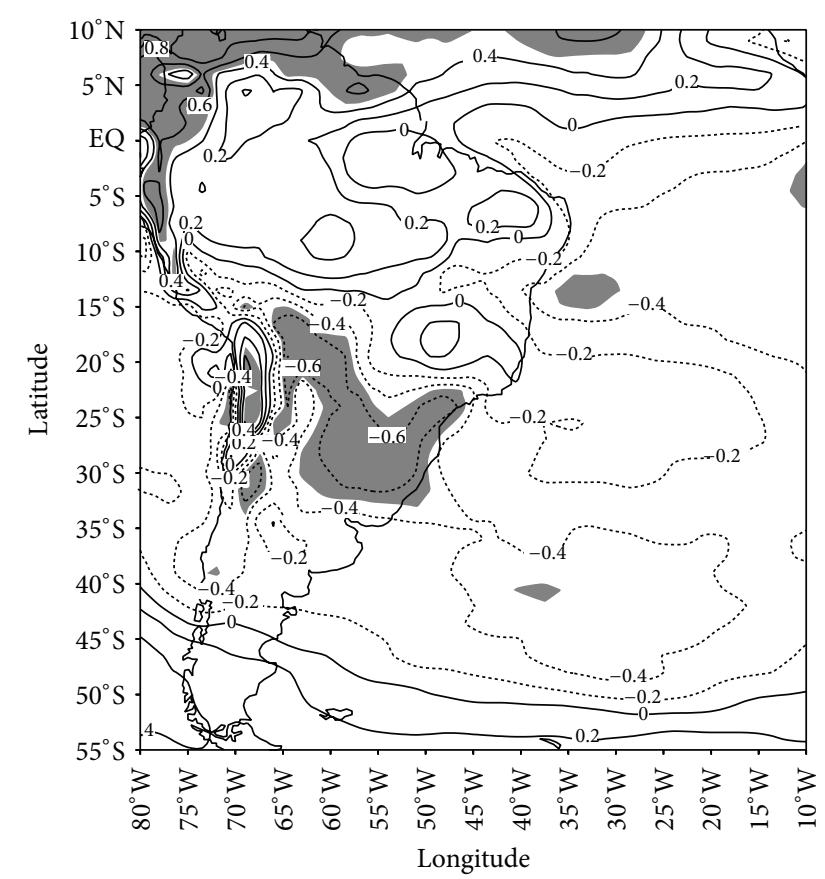

(b)

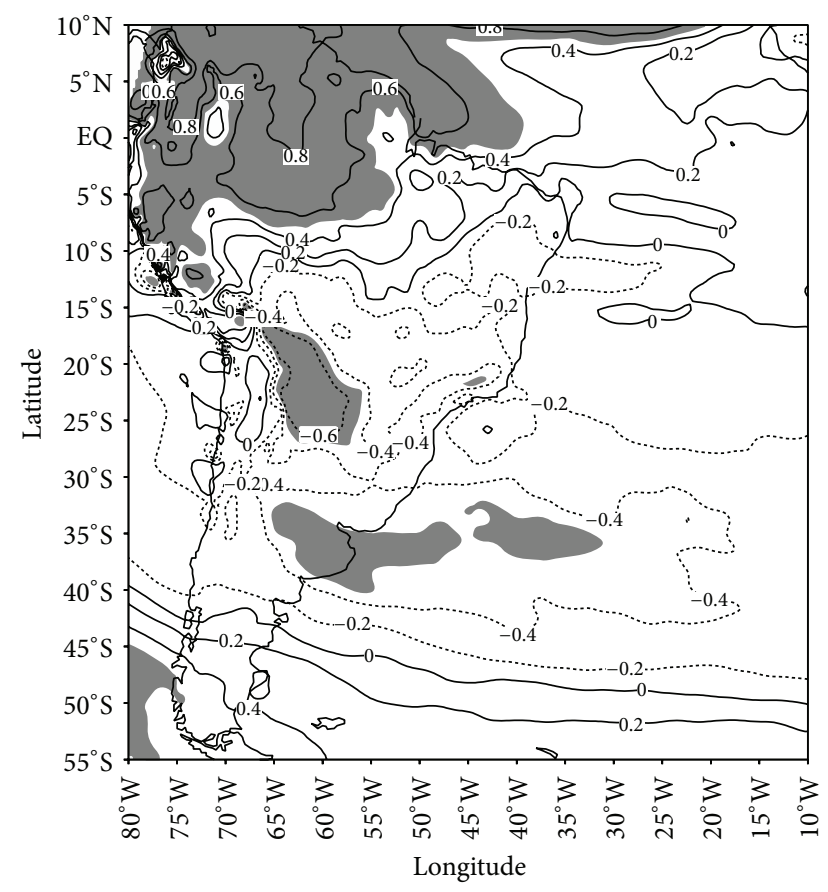

(d)

FIGURE 8: Correlation between the HCSA annual intensity index and the annual mean zonal wind ( $\mathrm{m} \mathrm{s}^{-1}$ ) in the period 1996-2011 based on the Era-Interim reanalysis at (a) $200 \mathrm{hPa}$ and (b) $850 \mathrm{hPa}$ and RegCM4 simulation at (c) $200 \mathrm{hPa}$ and (d) $850 \mathrm{hPa}$. Contour intervals are 0.2 and values above 0.5 are shaded and are statistically significant at $95 \%$ confidence level. For clarity purposes, it should be noted that the HCSA annual intensity index time series have been multiplied by $(-1)$. 


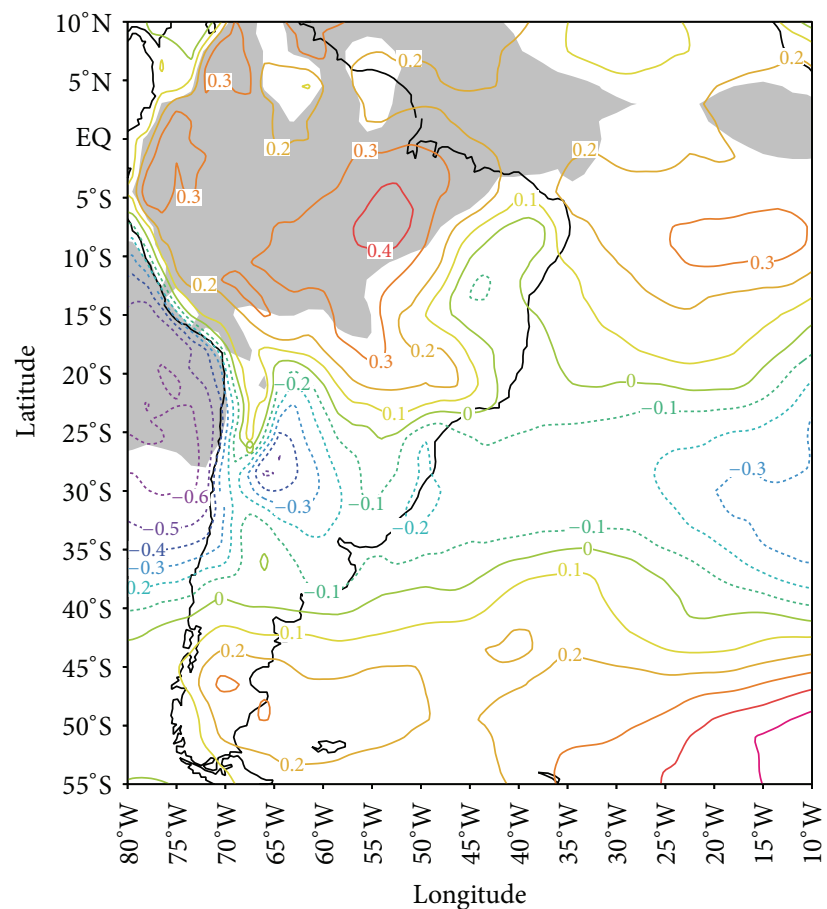

(a)

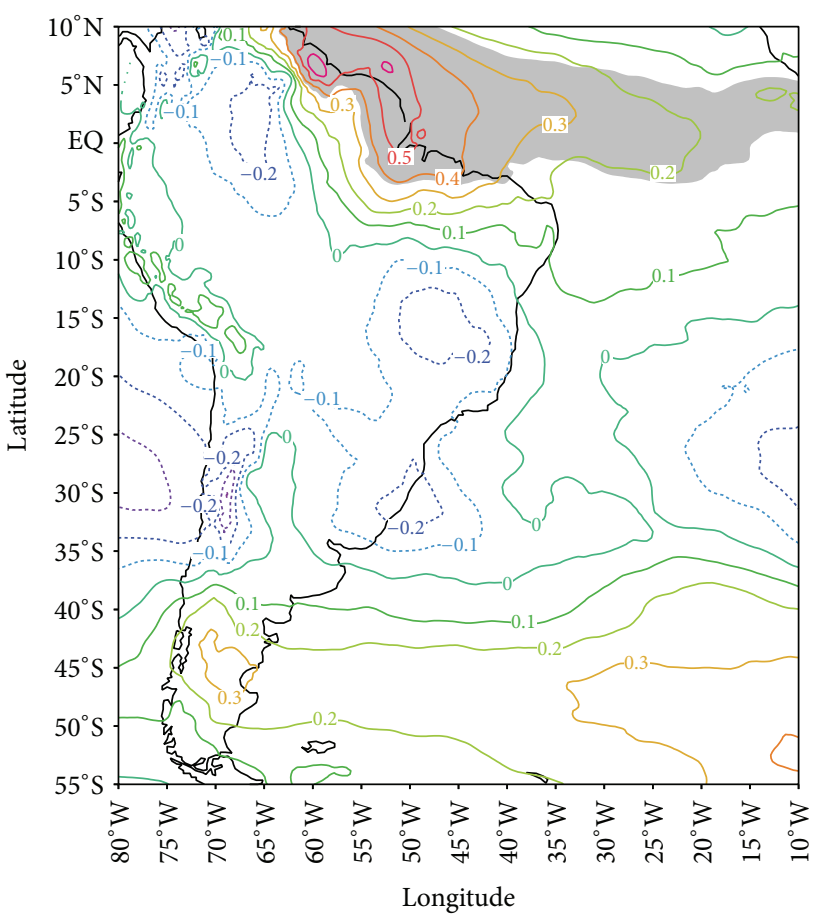

(b)

FIGURE 9: Annual mean temperature (K) anomaly at $850 \mathrm{hPa}$ for HCSA strong cases in the period 1996-2011 based on the (a) Era-Interim reanalysis and (b) RegCM4 simulation. Contour intervals are $0.1 \mathrm{~K}$ and significant values above $90 \%$ confidence level from two-tailed Student's $t$-test are shaded.

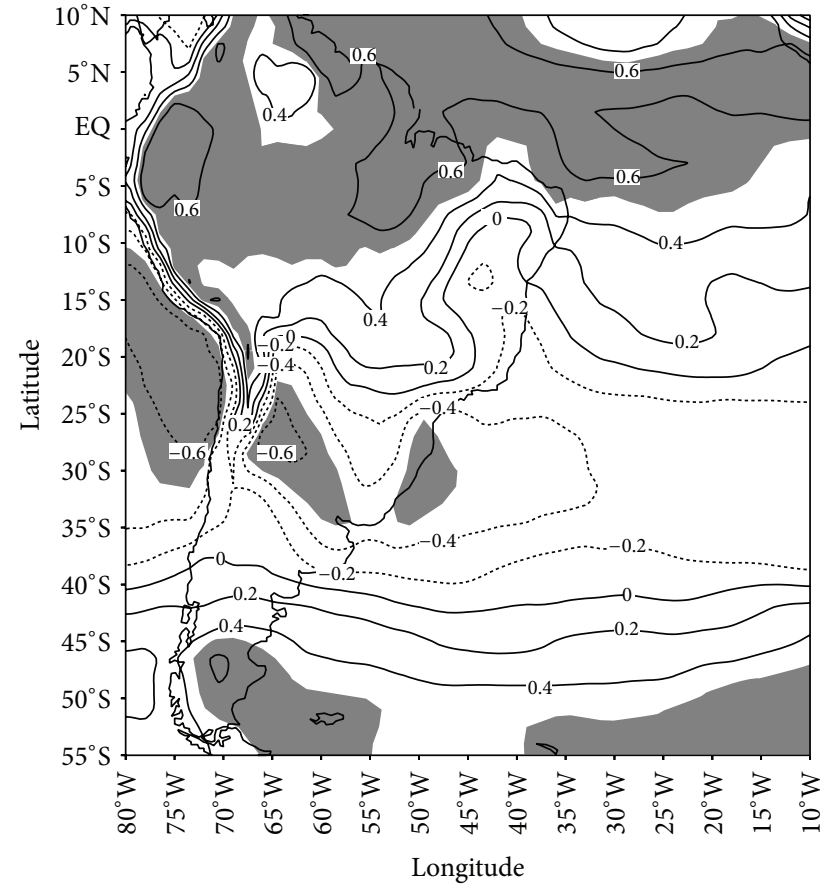

(a)

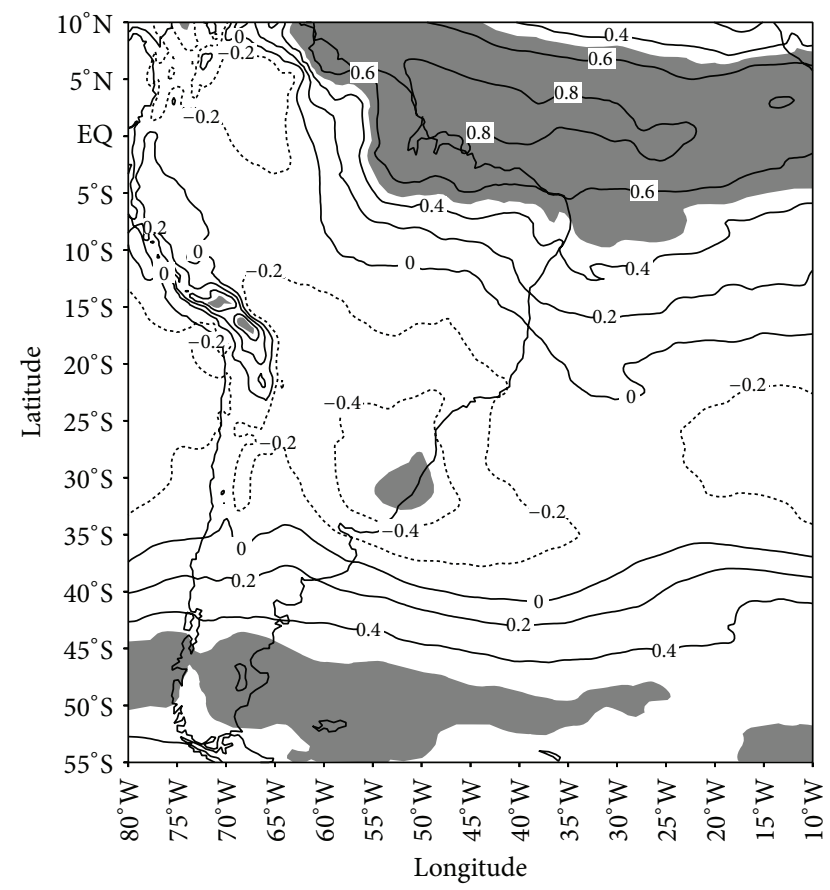

(b)

FIGURE 10: Correlation between the HCSA annual intensity index and the annual mean temperature (K) at $850 \mathrm{hPa}$ in the period $1996-$ 2011 based on the (a) Era-Interim reanalysis and (b) RegCM4 simulation. Contour intervals are 0.2 and values above 0.5 are shaded and are statistically significant at 95\% confidence level. For clarity purposes, it should be noted that the HCSA annual intensity index has been multiplied by $(-1)$. 


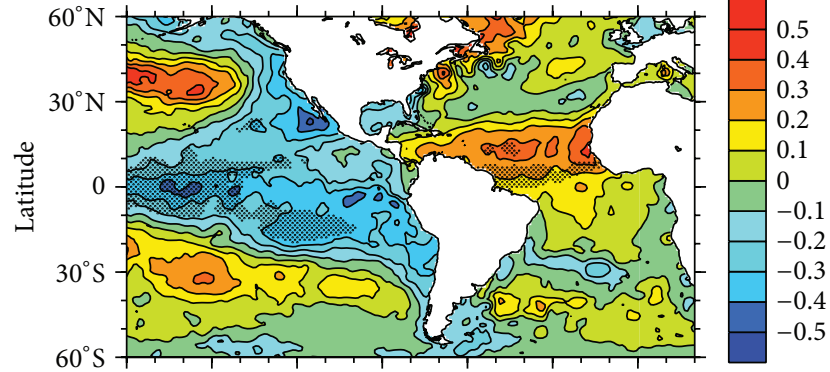

$180150^{\circ} \mathrm{W} \quad 120^{\circ} \mathrm{W} \quad 90^{\circ} \mathrm{W} \quad 60^{\circ} \mathrm{W} \quad 30^{\circ} \mathrm{W} \quad 0$ Longitude

Figure 11: Annual mean sea surface temperature (K) anomaly for HCSA strong cases in the period 1996-2011 based on the HADISST dataset. Contour intervals are $0.1 \mathrm{~K}$ with stippling indicating regions statistically significant above the $95 \%$ confidence level as determined by two-tailed Student's $t$-test.

SA and South Atlantic (Figures 10 and 8). Then, we can state that a cold trough is observed in the central regions of SA and South Atlantic and a warm ridge is seen over the southern SA and South Atlantic around $50^{\circ} \mathrm{S}$ when the HCSA strengthens (Figures 7, 8, and 10).

The significant positive temperature anomalies seen on a great part of northern SA (Figure 9(a)) indicates a strengthening of the Amazon heat source, which is linked to a strong HCSA ascending branch. On the other hand, the temperature anomalies seen over the Atlantic Ocean and eastern Pacific (Figure 9) are closely related to the SST anomalies for the HCSA strong cases (Figure 11). A La Niña pattern is observed in the equatorial Pacific region, whereas over the Atlantic Ocean, from 0 to $20^{\circ} \mathrm{N}$, positive SST anomalies are seen. The HCSA strong cases are 2005, 2008, 2010, and 2011 years. Weak La Niña episodes were observed during 2005-2006 and 2008-2009, and moderate to strong La Niña events were observed during 2010-2011 (historical ENSO episodes (1950-present) http://www.cpc.noaa.gov/ products/analysis_monitoring/ensostuff/ensoyears.shtml).

The Pacific Walker circulation for the HCSA strong cases (Figure 12(b)) shows some anomalous features compared to the climatology (Figure 12(a)), which are also seen during La Niña events [9]. For instance, around $180^{\circ}$ intense subsidence is seen, whereas in the eastern Pacific (around $90^{\circ} \mathrm{W}$ ) the downward motion is weaker (Figure 12(b)). Upward motion is observed in the western Pacific (around $130^{\circ} \mathrm{E}$ ), as also seen in the climatology (Figure 12(a)).

The strong ascending branch of the Walker circulation over northern SA (around $70^{\circ} \mathrm{W}$ ) is seen in the climatology (Figure 12(a)) and also for the HCSA strong cases (Figure 12(b)). Anomalous upward motion is also seen along the Atlantic basin (strongest at higher levels) (Figure 12(b)), due to positive SST anomalies from 0 to $20^{\circ} \mathrm{N}$ (Figure 11 ). These positive SST anomalies, centered at $15^{\circ} \mathrm{N}$, are associated with the weakening of the northern trade winds (Figure 6(b)), which usually blow southwestward toward the equator. On the other hand, the trade winds on the equator intensify (Figure 6(b)). These features seem to be related to a
TABLE 3: Area averaged root mean square error (RMSE) and bias and spatial correlation coefficient (CC) for the annual mean precipitation $\left(\mathrm{mm} \mathrm{day}^{-1}\right)$ anomalies for HCSA strong cases over the last three regions of Figure 5 in the period 1996-2011.

\begin{tabular}{lccc}
\hline Region & RMSE $\left._{(\mathrm{mm} \mathrm{day}}{ }^{-1}\right)$ & BIAS $\left(\mathrm{mm} \mathrm{day}^{-1}\right)$ & CC \\
\hline 5 & 0.47 & 0.11 & 0.74 \\
6 & 0.25 & -0.10 & 0.63 \\
7 & 0.52 & 0.14 & 0.34 \\
\hline
\end{tabular}

"new-type" Atlantic Niños events described by Richter et al. [37]. During "normal" Atlantic Niños, ocean temperatures warm up right on the equator due to the weakening of the surface winds. On the other hand, during the "newtype," positive SST anomalies are found north of the equator due to the weakening of the northern trade winds and the strengthening of the westward-directed winds on the equator. We can also see that the anomalous ascending branch of the HCSA is shifted northward (Figure 3(a)) compared to the climatology (Figure 1(a)) due to these positive SST anomalies found north of the equator.

The maximum of the annual total rainfall observed over SA, during the period 1996-2011, occurs mainly over the northern region from $7^{\circ} \mathrm{N}$ to $10^{\circ} \mathrm{S}$ and over the south of Brazil (figure not shown). The importance of the ENSO in modulating South American precipitation is well known through its associated changes in atmospheric circulation [38]. The SA rainfall distribution during La Niña events seen in the summer and autumn seasons is characterized by above average precipitation in the north and northeast part of SA and below normal values in the southern part of the continent [9]. Figure 13 shows that the annual anomalous rainfall distribution, during the HCSA strong cases analyzed, follows approximately the La Niña canonical impacts, especially over the south of Brazil and Uruguay (negative rainfall anomalies), but also presents the influence of the positive SST anomalies in Atlantic ("new-type" Atlantic Niños), especially over the edge of northeast SA (mostly negative rainfall anomalies).

Thus, the main regions of SA affected by the precipitation anomalies, which were selected for model evaluation, are the southeast, which encompasses the south of Brazil, Uruguay, and Argentina (region 5 of Figure 5), and the northeast (region 6 of Figure 5). Figure 13 and Table 3 show that the model overestimates the negative rainfall anomalies (bias = 0.11 ) over the southeast SA. However, this region presents the highest correlation between the model and observation (0.74). On the other hand, Figure 13 and Table 3 show that the rainfall anomalies observed in the northeast SA are underestimated by the model (bias $=-0.10$ ). When we consider all SA (region 7 of Figure 5), it is possible to note in Table 3 a weaker agreement between the model and observation for the precipitation anomalies (higher values of RMSE and absolute bias and lower value of correlation). Particularly, Figure 13 shows a weaker agreement between the model and observation in the region of Andes cordillera, indicating an overestimation of the precipitation, which is also documented in several studies (e.g., [39, 40]). The complex topography of the Andes with a high degree of convective precipitation provides 


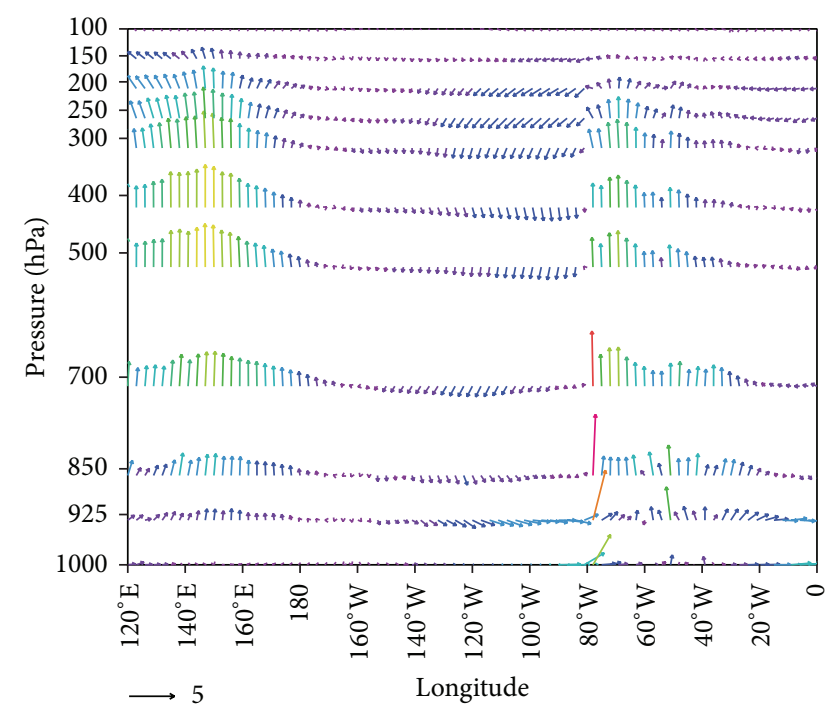

(a)

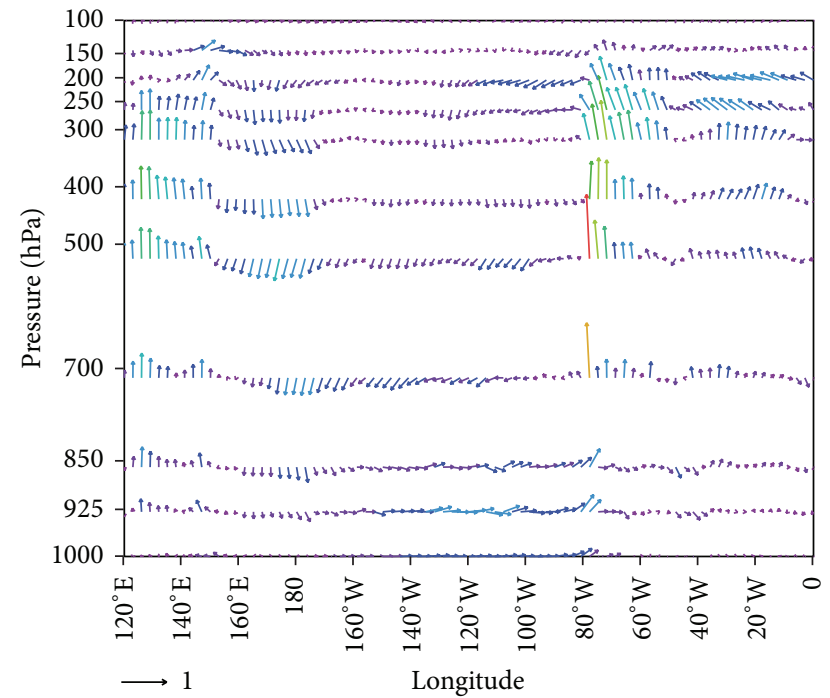

(b)

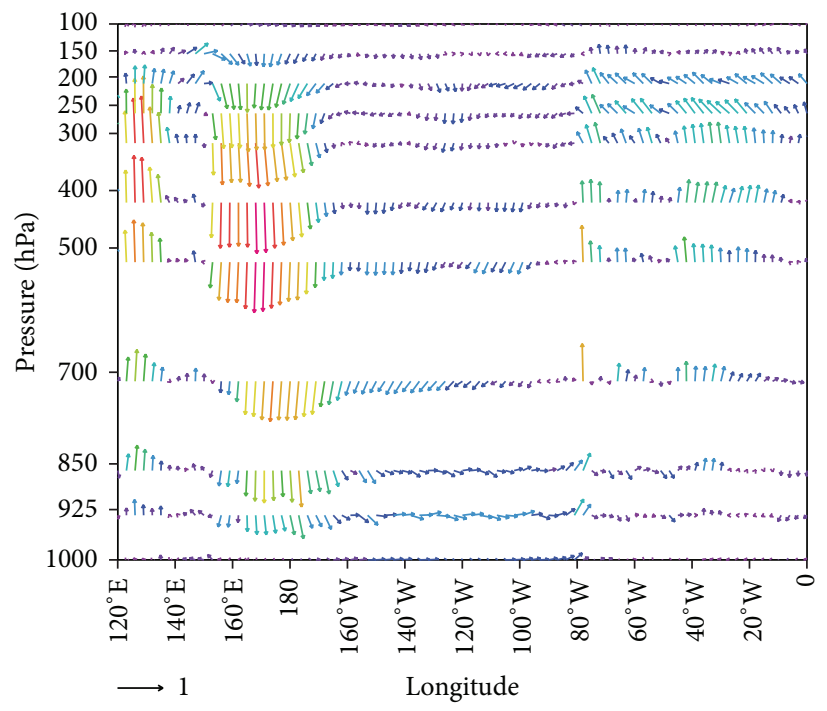

(c)

FIGURE 12: Walker circulation by averaging divergent wind and vertical velocity in the latitudinal band between $5^{\circ} \mathrm{S}$ and $5^{\circ} \mathrm{N}$ in the period 1996-2011 based on the Era-Interim reanalysis for (a) climatological annual mean and anomalies for (b) HCSA strong cases and (c) HCSA poleward expansion cases. The color scale represents the vector's magnitude. The reference vector in (a) corresponds to $5 \mathrm{~m} \mathrm{~s}^{-1}$ whereas in (b) and (c) it is $1 \mathrm{~m} \mathrm{~s}^{-1}$.

a particularly difficult challenge for model performance. Besides, the Andes region is characterized by very sparse data availability, which is one of the major shortcomings for evaluating model performance over the South American continent. Increasing the model resolution can improve the results. Rojas [40] found that, for climate change studies, the horizontal resolution required to reproduce adequate rainfall patterns over the central Andes region is around 30 to $40 \mathrm{~km}$. Also, it is important to remember that these model results are sensitive to the choice of the convective scheme. In this paper, the Kuo scheme was chosen, but Fernandez et al. [39] found that the precipitation is in general better simulated with the Grell scheme than the Kuo scheme.
Chen et al. [6] found disagreements in the regional HCs intensity trends among six different reanalyses (Era-Interim, ERA-40, NCEP1, NCEP2, JRA25, and 20CR). For the HC over SA, the authors showed that all six reanalyses present an intensification trend, although not all are statistically significant. The authors also found high correlation values for the intensity index of the HC over SA between the EraInterim and ERA-40 and NCEP2 and JRA25 reanalyses $(0.89$, 0.76 , and 0.64 , resp.), whereas lower correlation values are seen with the 20CR and NCEP1 reanalyses (0.47 and 0.42 , resp.). It is worth remembering that these both reanalyses (20CR and NCEP1) present some well-known issues. In the 20CR, only surface pressure observations are assimilated, 


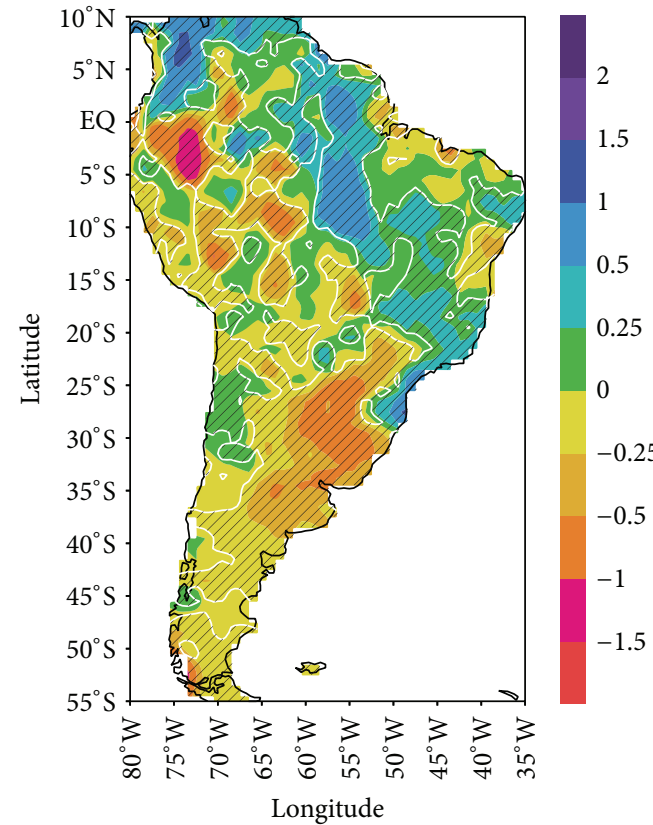

(a)

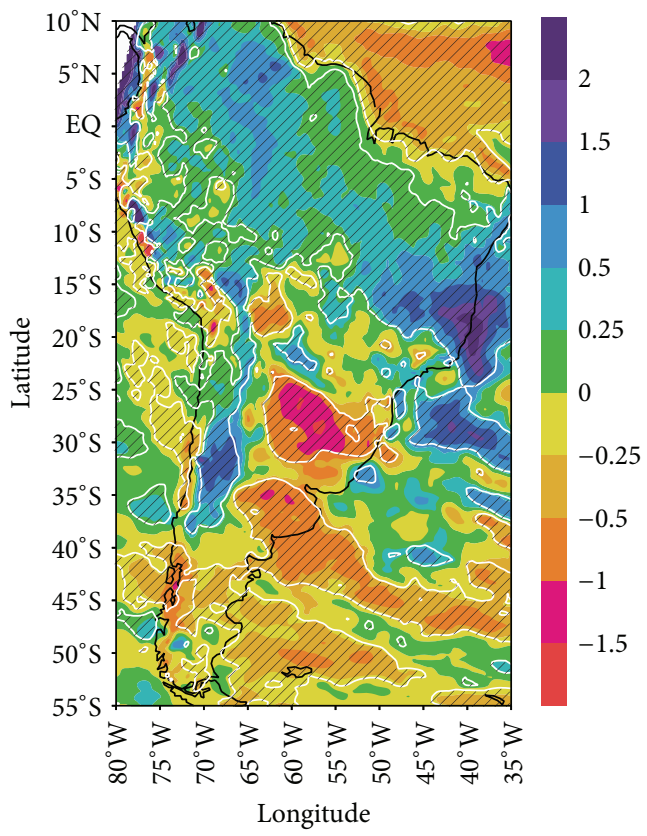

(b)

FIGURE 13: Precipitation anomaly $\left(\mathrm{mm} \mathrm{day}^{-1}\right)$ for HCSA strong cases in the period 1996-2011 based on the (a) GPCC dataset and (b) RegCM4 simulation. Contour intervals are $0.25 \mathrm{~mm} \mathrm{day}^{-1}$ with hatching indicating regions statistically significant above the $95 \%$ confidence level as determined by two-tailed Student's $t$-test.

and, therefore, there is a potential for large differences, especially in vertical structure, between this dataset and other reanalyses. On the other hand, in the NCEP1 reanalysis, the potential for differences rises due to the change in quantity and spatial coverage of the observed data, especially from the beginning of the major satellite era. Thus, the results found here for the HCSA intensification present some sensitivity to the reanalysis used. However, we believe that they are reliable, as the Era-Interim represents a newer-generation reanalysis that incorporates many important model improvements and, according to several studies (e.g., [31, 32]), has the best performance among reanalysis datasets.

\section{Impacts of the HCSA Poleward Expansion}

Figure 14 shows the anomalies of the annual mean horizontal wind at 200 and $850 \mathrm{hPa}$ for the HCSA poleward expansion cases based on the Era-Interim reanalysis and model simulation. Here, as for the HCSA strong cases, anomalous easterly winds coming from the Atlantic Ocean are seen over northern SA at $200 \mathrm{hPa}$ in the reanalysis (Figure 14(a)) and model simulation (Figure 14(c)). These anomalous winds present in northern SA are weaker compared to those seen for HCSA strong cases (Figures 6(a) and 6(c)). Around $40^{\circ} \mathrm{S}$, strong anomalous winds for HCSA poleward expansion cases are observed coming from the Atlantic Ocean and hitting the southeast SA (Figures 14(a) and 14(c)). However, when entering the mainland these winds become weaker and rotate clockwise. This results in a significant anomalous trough, which is seen in reanalysis and model simulation at $200 \mathrm{hPa}$ (Figure not shown) and $500 \mathrm{hPa}$ over the central region of SA (Figure 15). The center of this trough is over the central Atlantic basin, where the anomalous easterly winds are stronger (Figures 14(a) and 14(c)). This trough is more intense compared to that seen for the HCSA strong cases (Figure 7).

The anomalous wind pattern at $850 \mathrm{hPa}$ is characterized by the weakening of the trade winds around equator and a counterclockwise circulation in the South Atlantic around $50^{\circ} \mathrm{S}$ in the reanalysis (Figure 14(b)) and simulation (Figure 14(d)). This counterclockwise circulation results in a significant anomalous ridge, which is observed at $850 \mathrm{hPa}$ (Figure not shown) and at $500 \mathrm{hPa}$ over the southern SA and especially over the southern of Atlantic basin, in the reanalysis and simulation (Figure 15). Strong anomalous westerly winds coming from the eastern Pacific cross the southern SA (Figures 14(b) and 14(d)) and contribute to the formation of this ridge. This ridge is more intense over the southern SA and Atlantic Ocean compared to that seen for the HCSA strong cases (Figure 7) and is associated with the robust descending branch of the HCSA (Figure 3(b)).

The correlation between the HCSA annual poleward edge time series and the annual mean zonal wind at 200 and $850 \mathrm{hPa}$ in the period 1996-2011 is displayed in Figure 16. The correlation signs (positives and negatives) are the same observed for the HCSA strong cases (Figure 8), though the statistically significant regions are different. At $200 \mathrm{hPa}$, the reanalysis dataset presents two regions with significant negative correlations (over Peru and Atlantic Ocean around 


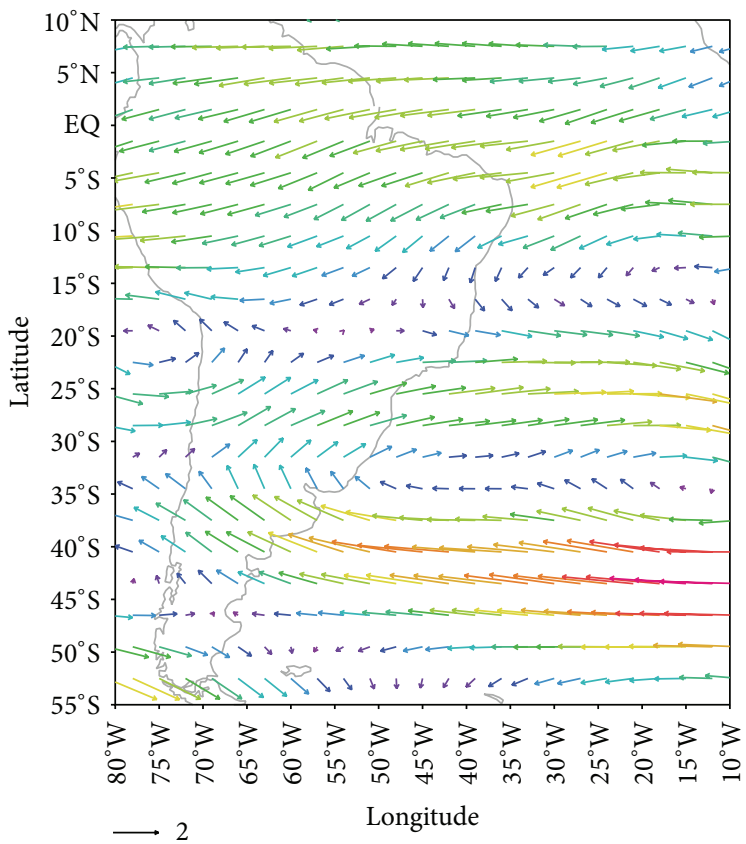

(a)

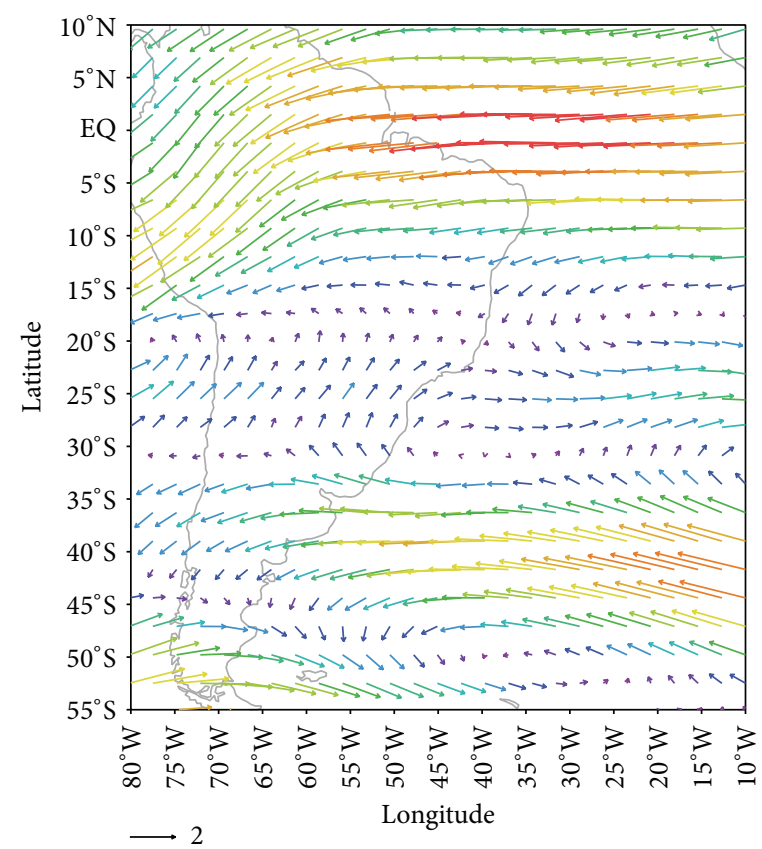

(c)

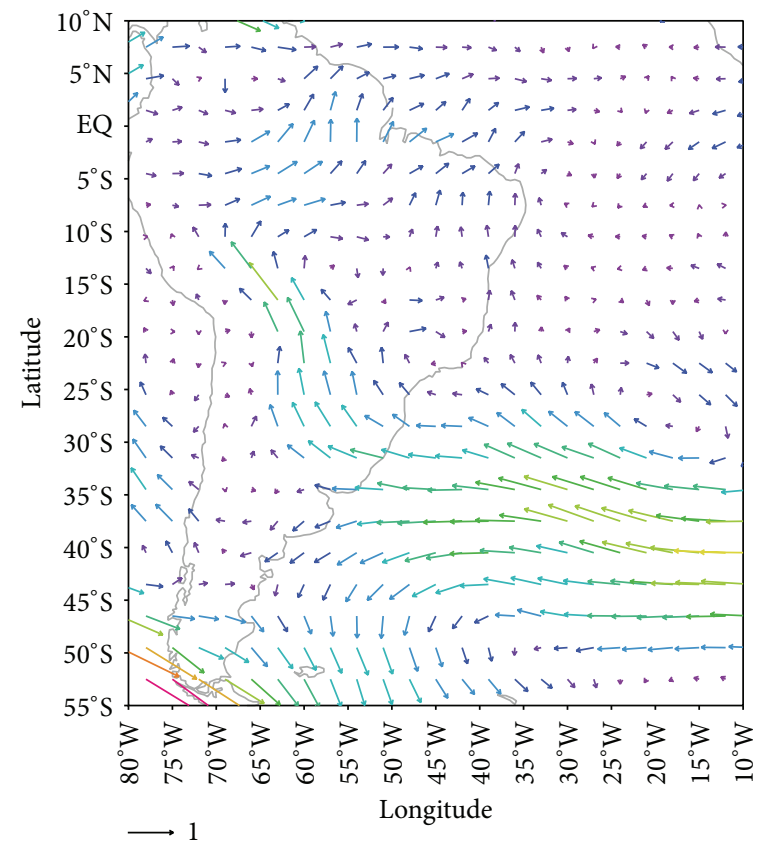

(b)

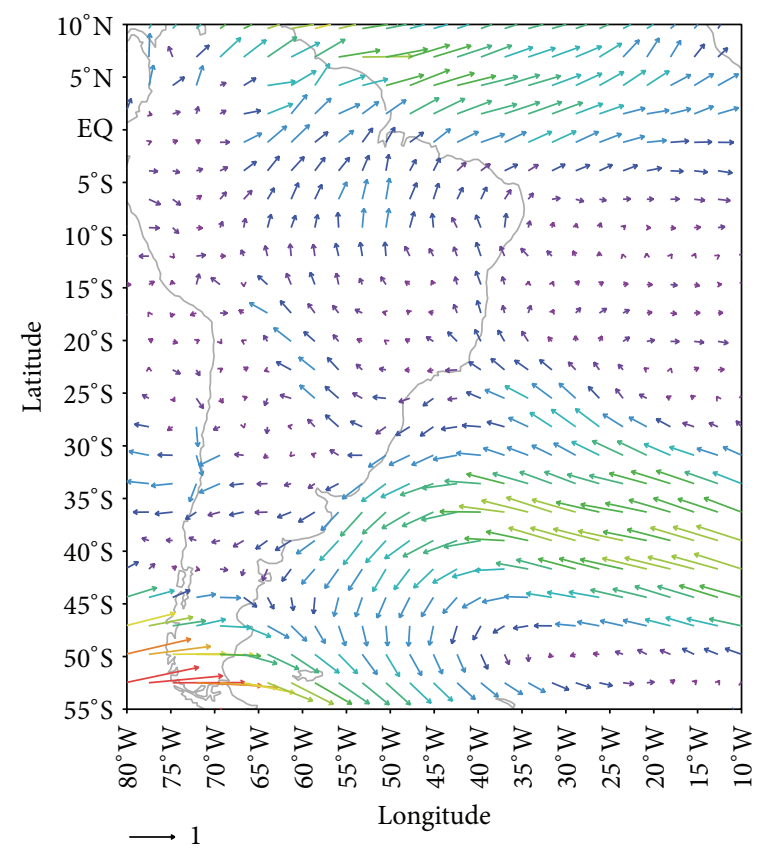

(d)

FIGURE 14: Annual mean horizontal wind $\left(\mathrm{m} \mathrm{s}^{-1}\right)$ anomaly for HCSA poleward expansion cases in the period 1996-2011 based on the EraInterim reanalysis at (a) $200 \mathrm{hPa}$ and (b) $850 \mathrm{hPa}$ and RegCM4 simulation at (c) $200 \mathrm{hPa}$ and (d) $850 \mathrm{hPa}$. The color scale represents the vector's magnitude.

$45^{\circ} \mathrm{S}$ ) and two other regions with significant positive correlations (over the southern SA and the central area of South Atlantic) (Figure 16(a)). The model simulation presents smaller and not significant correlations for the central areas of SA and South Atlantic (Figure 16(c)). The correlation map at
$850 \mathrm{hPa}$ shows regions with significant positive and negative correlations over the southern SA and over the south of Brazil and south of Atlantic around $15^{\circ} \mathrm{W}$, respectively, in the reanalysis and model simulation (Figures 16(b) and 16(d)). Here, as also seen for the HCSA strong cases, regions with 
TABLE 4: Area averaged root mean square error (RMSE) and bias and spatial correlation coefficient (CC) for the zonal wind ( $\mathrm{m} \mathrm{s}^{-1}$ ) at $200 \mathrm{hPa}$ (ZW200) and $850 \mathrm{hPa}(\mathrm{ZW} 850)$, geopotential height $(\mathrm{m})$ at $500 \mathrm{hPa}(\mathrm{GH})$, and air temperature (K) at $925 \mathrm{hPa}(\mathrm{AT})$ anomalies for HCSA poleward expansion cases over the first four regions of Figure 5.

\begin{tabular}{ccccccccccccc}
\hline \multirow{2}{*}{ Region } & \multicolumn{9}{c}{ RMSE } & \multicolumn{9}{c}{ BIAS } & \multicolumn{4}{c}{ CC } \\
& ZW200 & ZW850 & GH & AT & ZW200 & ZW850 & GH & AT & ZW200 & ZW850 & GH & AT \\
\hline 1 & 0.44 & 0.26 & 2.24 & 0.24 & -0.13 & 0.09 & 1.59 & -0.13 & 0.72 & 0.45 & 0.20 & 0.31 \\
2 & 0.82 & 0.15 & 3.93 & 0.17 & -0.60 & -0.02 & 3.78 & -0.04 & 0.79 & 0.75 & 0.86 & 0.39 \\
3 & 0.61 & 0.22 & 2.14 & 0.10 & 0.50 & 0.13 & 2.03 & 0.03 & 0.96 & 0.97 & 0.99 & 0.81 \\
4 & 0.69 & 0.24 & 3.34 & 0.17 & -0.23 & 0.09 & 2.65 & -0.02 & 0.87 & 0.85 & 0.94 & 0.70 \\
\hline
\end{tabular}

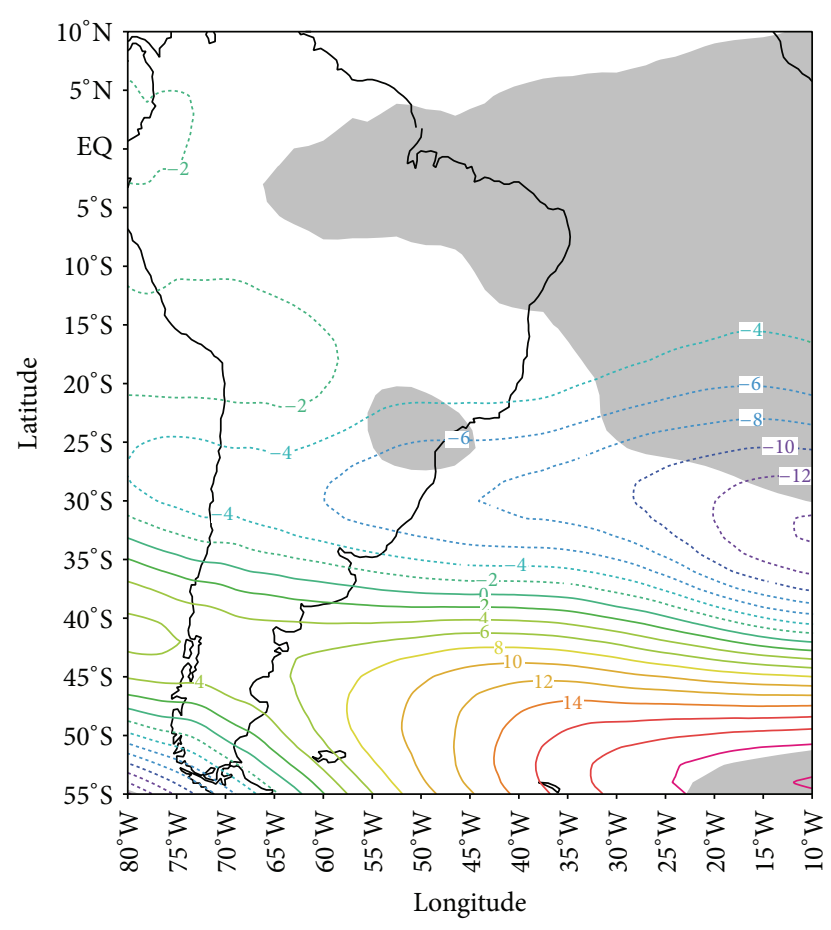

(a)

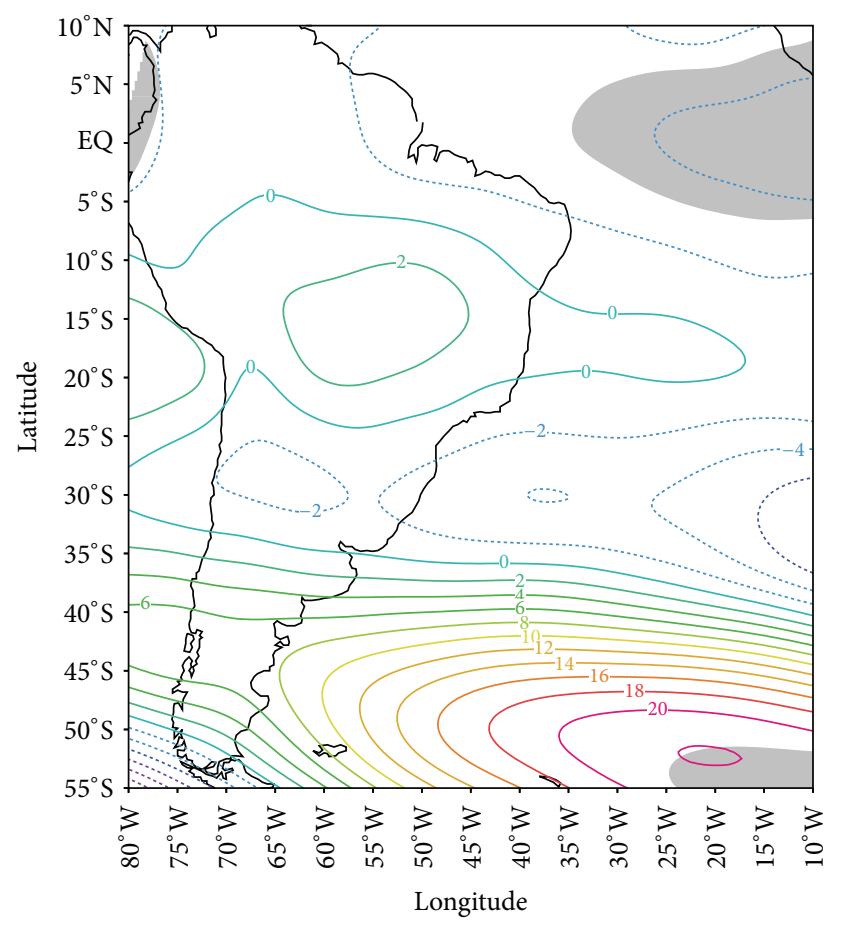

(b)

Figure 15: Annual mean geopotential height (m) anomaly for HCSA strong cases at $500 \mathrm{hPa}$ in the period 1996-2011 based on the (a) EraInterim reanalysis and (b) RegCM4 simulation. Contour intervals are $2 \mathrm{~m}$ and significant values above $90 \%$ confidence level from two-tailed Student's $t$-test are shaded.

anomalous easterly (westerly) winds coming from (towards) the Atlantic Ocean have negative (positive) correlations with the HCSA poleward edge.

Table 4 shows that, for the zonal wind anomalies at $200 \mathrm{hPa}$, the northern SA exhibits weaker spatial correlation between the model and observation (0.72), although the values of RMSE and bias (absolute value) are the lowest compared to the other regions. The central region exhibits the highest values of RMSE and bias for the anomalies of zonal wind at $200 \mathrm{hPa}$ and geopotential height at $500 \mathrm{hPa}$, whereas the opposite is found for the zonal wind anomalies at $850 \mathrm{hPa}$. Theses aspects were also verified for the HCSA strong cases (Table 2). The southern SA exhibits the highest spatial correlation for the anomalies of zonal wind at 200 and $850 \mathrm{hPa}$ and geopotential height at $500 \mathrm{hPa}(0.96,0.97$, and 0.99 , resp.). As well, these correlation values are greater than for the HCSA strong cases.
Figure 17 displays the annual mean temperature anomaly for the HCSA poleward expansion cases. Significant positive anomalies are seen in the reanalysis over northern SA (between 0 and $5^{\circ} \mathrm{S}$ and $60^{\circ}$ and $45^{\circ} \mathrm{W}$ ) (Figure $17(\mathrm{a})$ ), whereas negative anomalies are found over the east Pacific around $20^{\circ} \mathrm{S}$ in the reanalysis and model simulation (Figures 17(a) and 17(b)). Table 4 shows that the model underestimates the temperature anomalies in the northern region (bias = -0.13). As well, this region exhibits the highest values of RMSE and bias (absolute value) and the lowest value of correlation, indicating a weaker agreement between the model and observation compared to the other regions. It is worth remembering that the observational data are likely affected by significant uncertainties, particularly in remote areas of the Amazon basin, and this makes a rigorous model assessment over this region rather difficult. Moreover, local processes involving land-atmosphere interactions influence 


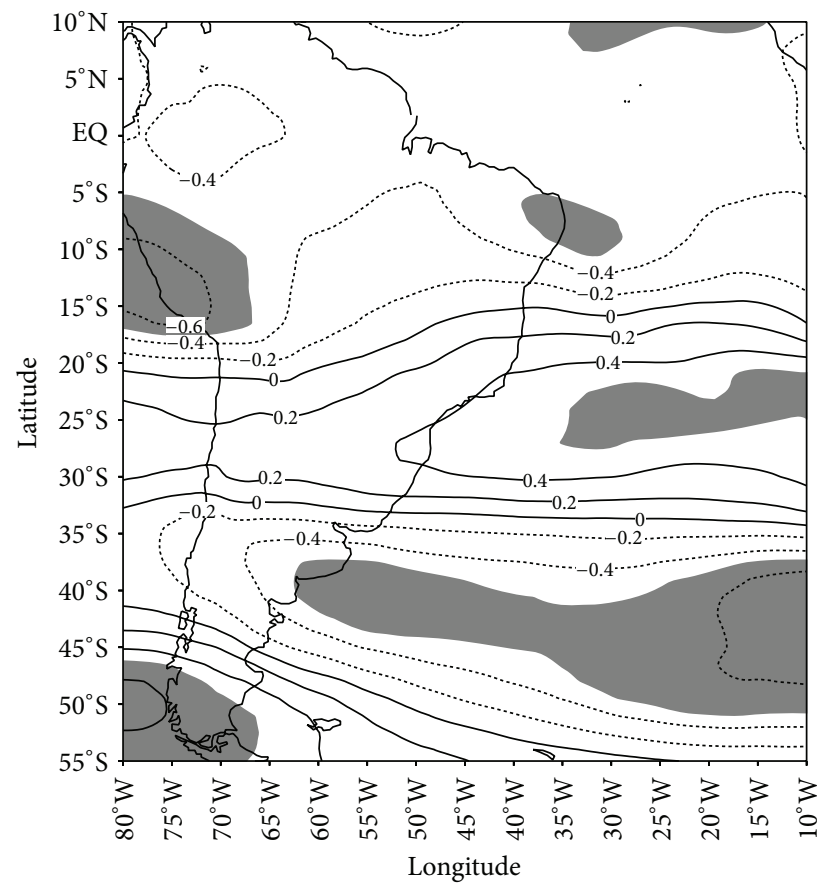

(a)

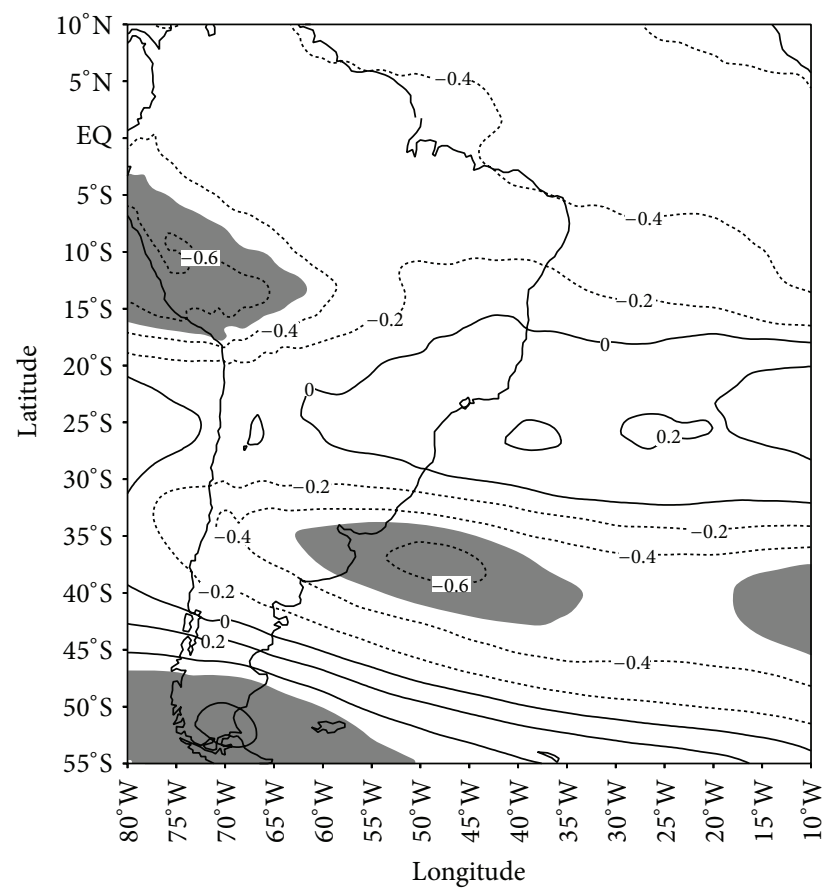

(c)

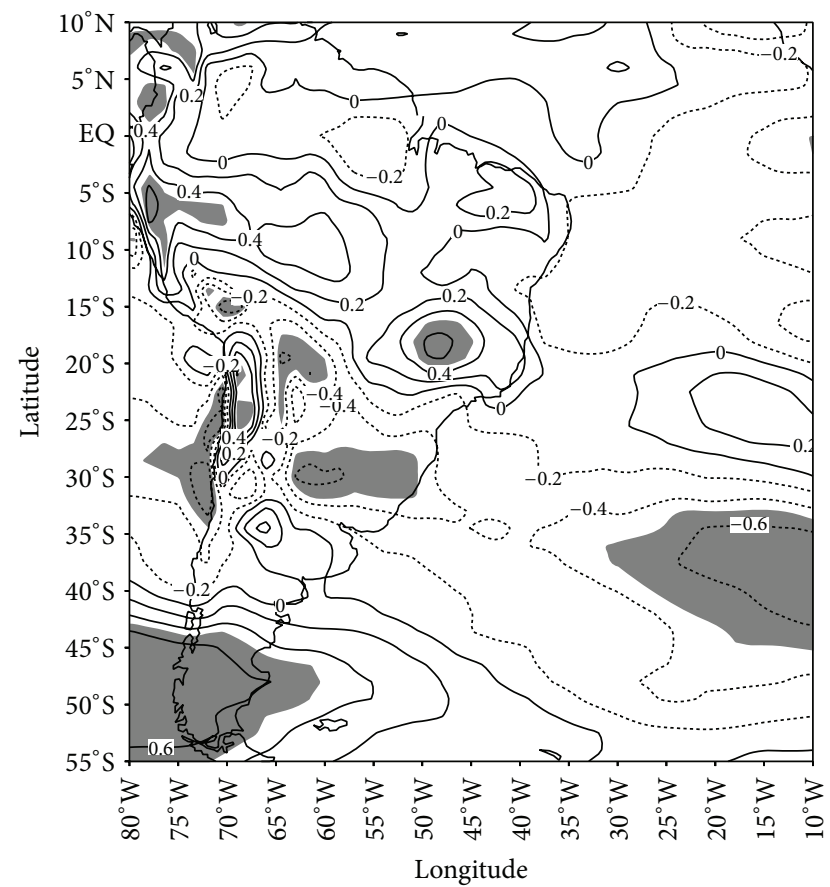

(b)

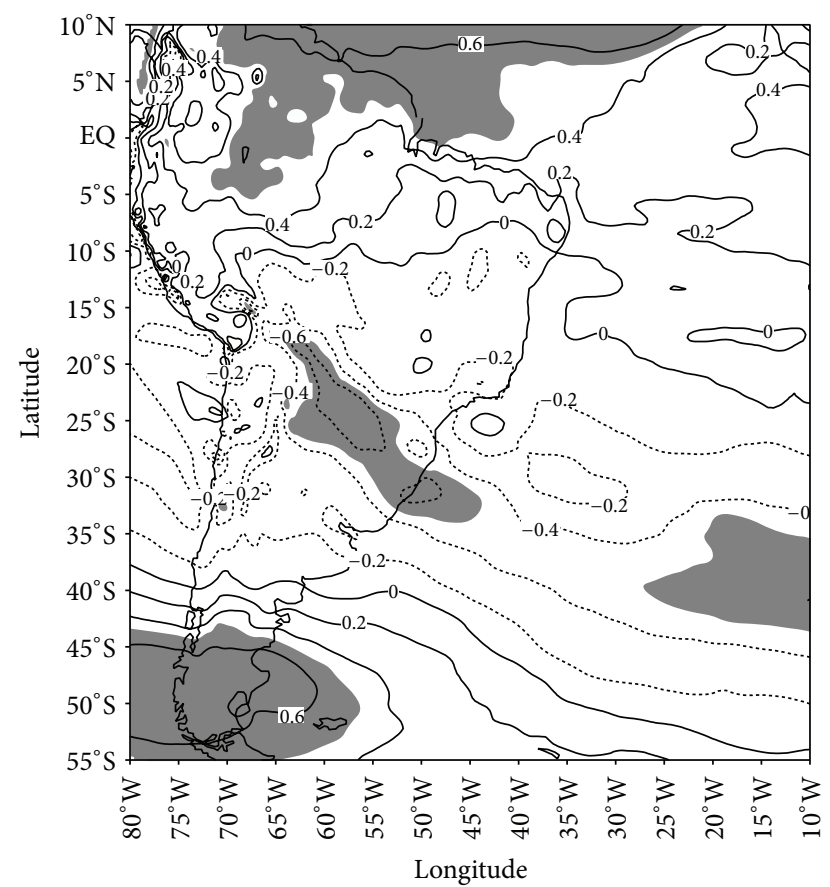

(d)

Figure 16: Correlation between the HCSA annual poleward edge time series and the annual mean zonal wind ( $\mathrm{m} \mathrm{s}^{-1}$ ) in the period 1996-2011 based on the Era-Interim reanalysis at (a) $200 \mathrm{hPa}$ and (b) $850 \mathrm{hPa}$ and RegCM4 simulation at (c) $200 \mathrm{hPa}$ and (d) $850 \mathrm{hPa}$. Contour intervals are 0.2 and values above 0.5 are shaded and are statistically significant at $95 \%$ confidence level. Here, the poleward edge is defined as the latitude where the OLR is equal to $240 \mathrm{~W} \mathrm{~m}^{-2}$. For clarity purposes, it should be noted that the HCSA annual poleward edge time series have been multiplied by $(-1)$. 


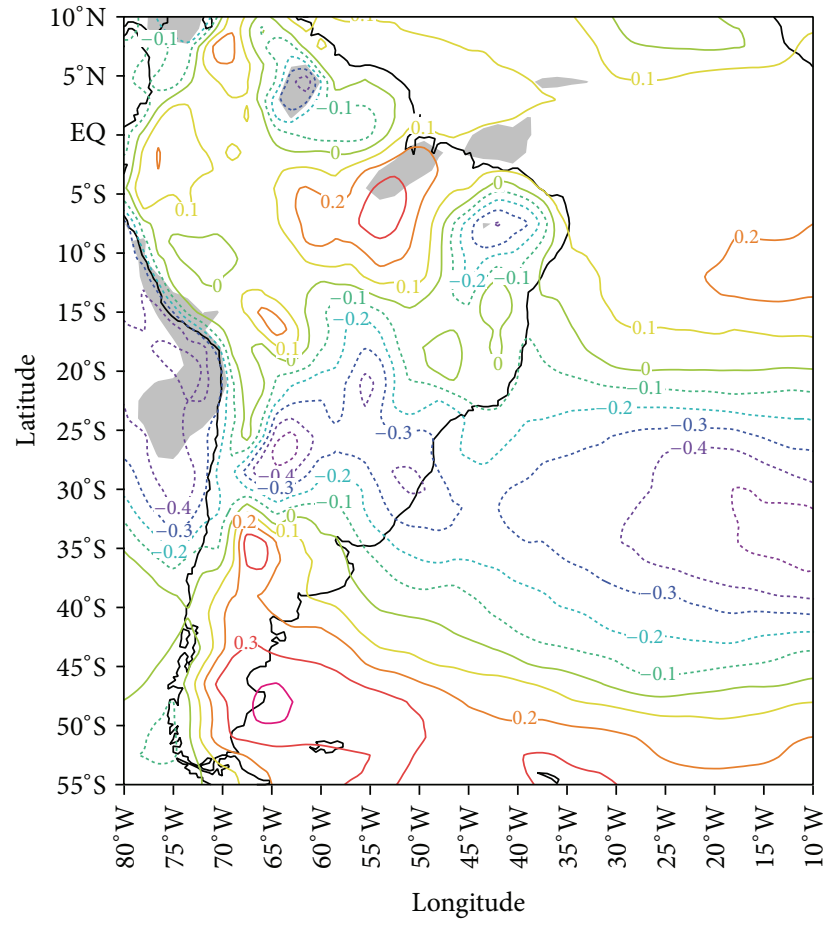

(a)

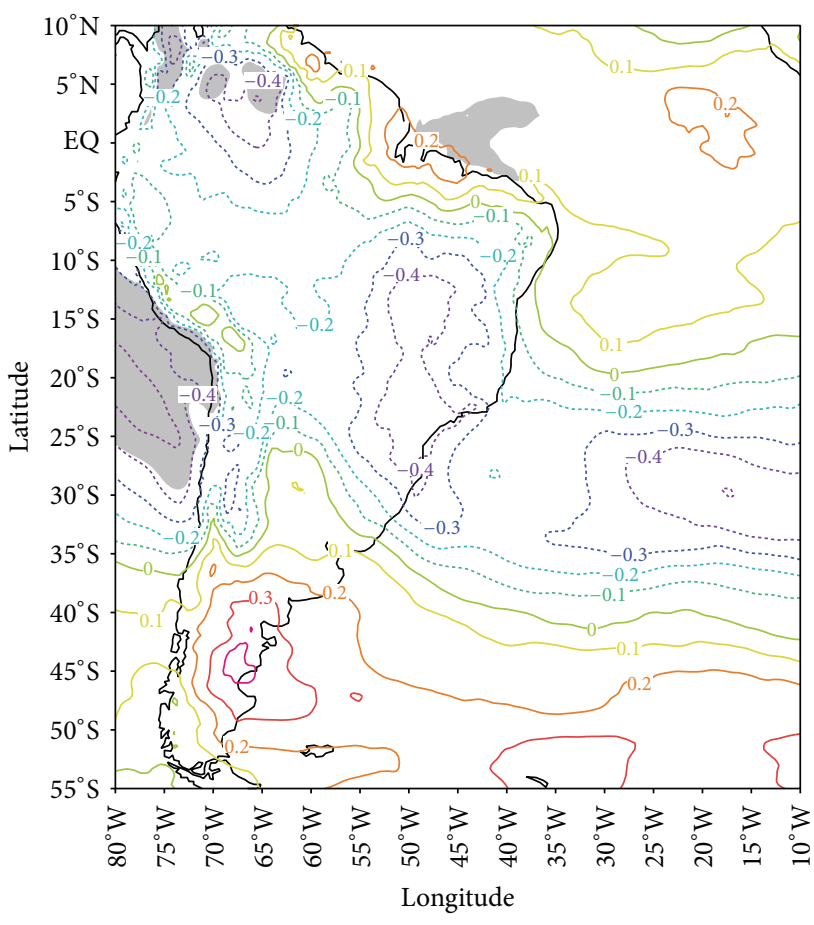

(b)

FIGURE 17: Annual mean temperature (K) anomaly at $925 \mathrm{hPa}$ for HCSA poleward expansion cases in the period 1996-2011 based on the (a) Era-Interim reanalysis and (b) RegCM4 simulation. Contour intervals are $0.1 \mathrm{~K}$ and significant values above $90 \%$ confidence level from two-tailed Student's $t$-test are shaded.

the surface climate of the Amazon basin; thus, the treatment of surface processes is crucial [11]. On the other hand, the southern region exhibits good agreement between the model and observation, with low values for RMSE and bias and high values for spatial correlation.

The temperature anomalies for the HCSA poleward expansion cases seem to be very similar to those found for the strong cases; however, there are differences in the statistically significant regions and/or the anomalies intensity. Compared to the HCSA poleward expansion cases, years that present HCSA intensification show significant positive anomalies over a great part of the northern region, reduced anomalies over the southern SA and the central area of the South Atlantic, and more intense positive anomalies over the northern regions of SA and South Atlantic (Figure 9(a)).

From the combination of Figures 15 and 17, one can conclude that a strong cold trough is observed in the central regions of SA and South Atlantic and a strong warm ridge is seen over the southern SA and South Atlantic around $50^{\circ} \mathrm{S}$ when the HCSA expands poleward. Here, as mentioned earlier, the trough and the ridge are more intense than for the HCSA strong cases (Figure 7).

Figure 18 displays the correlation between the HCSA annual poleward edge time series and the annual mean temperature at $925 \mathrm{hPa}$ in the period 1996-2011. This figure is similar to Figure 10, which shows the correlation between the $\mathrm{HCSA}$ intensity and the annual mean temperature at $850 \mathrm{hPa}$. However, the results show that in the HCSA strong cases, high correlations are seen over the northern regions of SA and South Atlantic (above 0.6). The correlations are smaller over these regions in the HCSA poleward expansion cases.

The temperature anomalies seen over the Atlantic Ocean and eastern Pacific (Figure 17) are connected with the SST anomalies for the HCSA poleward expansion cases (Figure 19). The La Niña pattern is also observed in the Pacific region, but with greater intensity in the equatorial region and weaker anomalies in the eastern Pacific around $20^{\circ} \mathrm{S}$ compared to the HCSA strong cases (Figure 11). Due to these facts, the Pacific Walker circulation here presents weaker downward motion in eastern Pacific (around $90^{\circ} \mathrm{W}$ ), stronger upward motion in western Pacific (around $130^{\circ} \mathrm{E}$ ), and more intense subsidence around $180^{\circ}$ compared to the HCSA strong cases (Figures 12(b) and 12(c)). The HCSA poleward expansion cases are 1996, 2008, 2010, and 2011 years. The three last years are common to both composites that represent the HCSA intensification and poleward expansion. Thus, the 1996 year is the differential for the HCSA poleward expansion composite and a La Niña event was also observed during 1995-1996 (Historical ENSO episodes (1950-present) http://www.cpc.noaa.gov/products/analysis_monitoring/ensostuff/ensoyears.shtml).

Over the Atlantic Ocean, positive SST anomalies are now seen from $20^{\circ} \mathrm{S}$ to $20^{\circ} \mathrm{N}$. Thus, here we see a southward extension and reduced intensity at the north of equator of the positive SST anomalies compared to HCSA strong cases (Figures 11 and 19). The HCSA ascending branch for poleward 


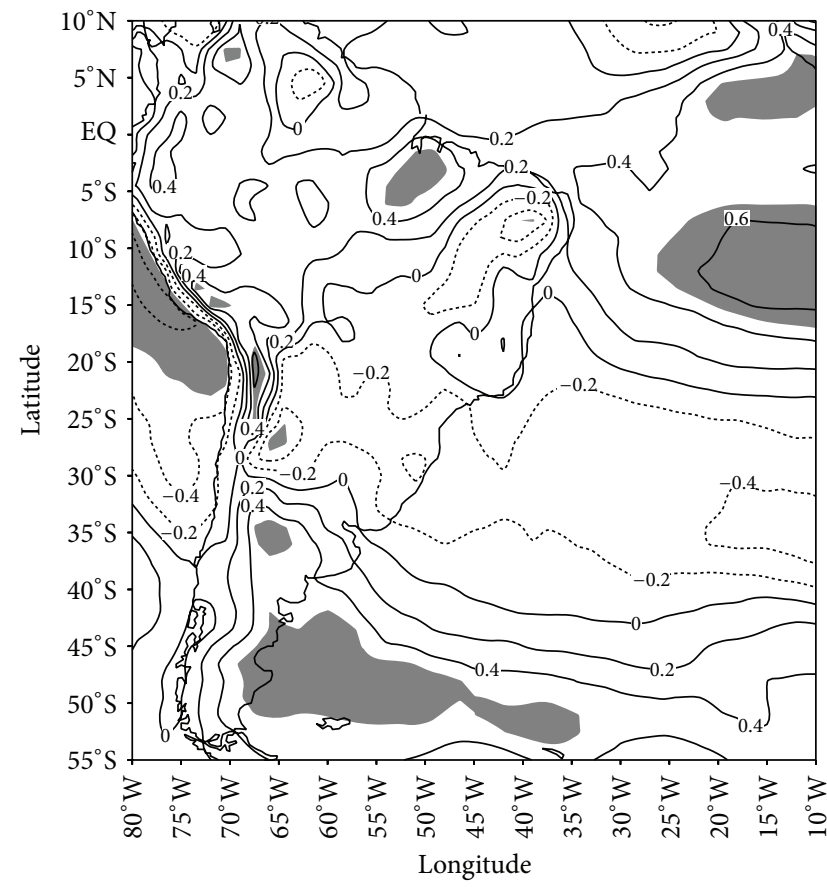

(a)

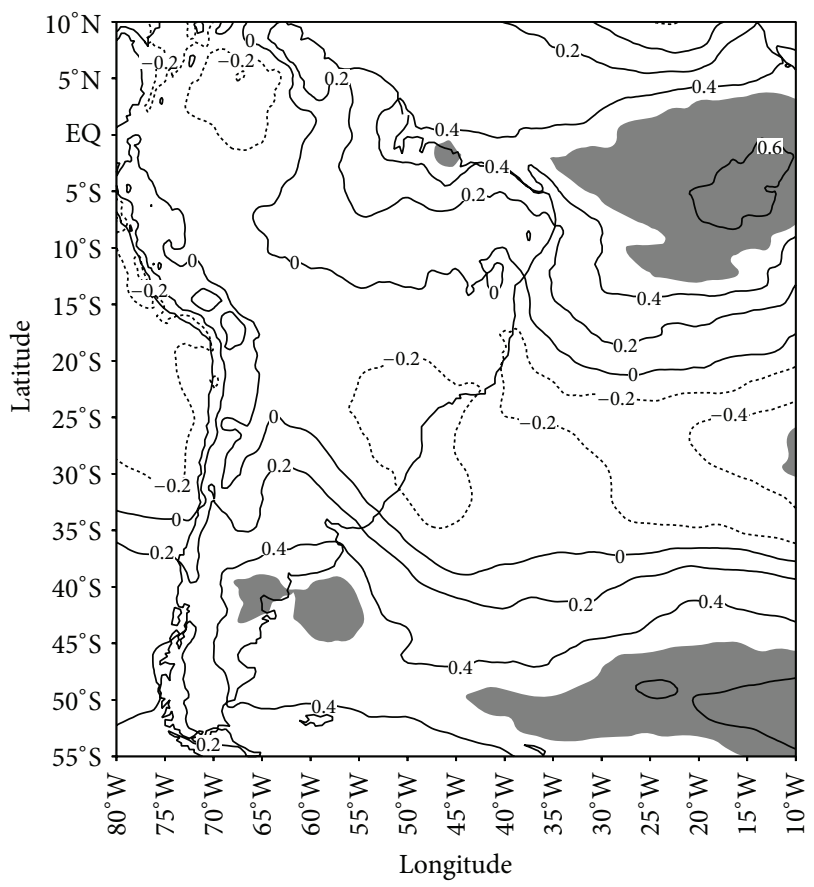

(b)

FIgURE 18: Correlation between the HCSA annual poleward edge time series and the annual mean temperature (K) at $925 \mathrm{hPa}$ in the period 1996-2011 based on the (a) Era-Interim reanalysis and (b) RegCM4 simulation. Contour intervals are 0.2 and values above 0.5 are shaded and are statistically significant at $95 \%$ confidence level. Here, the poleward edge is defined as the latitude where the OLR is equal to $240 \mathrm{~W} \mathrm{~m}^{-2}$. For clarity purposes, it should be noted that the HCSA annual poleward edge time series have been multiplied by $(-1)$.

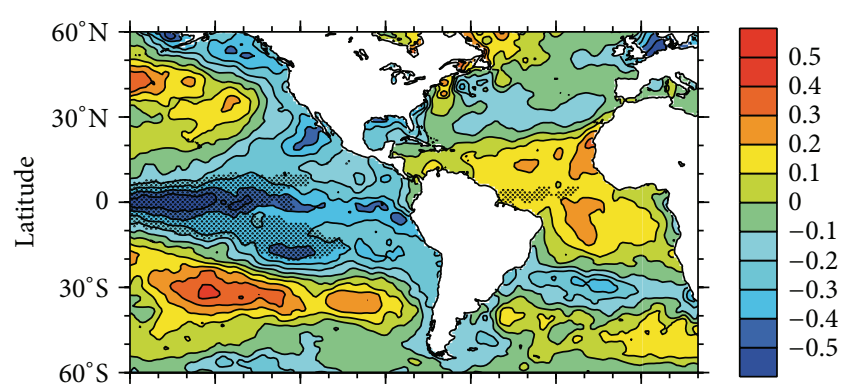

$180150^{\circ} \mathrm{W} \quad 120^{\circ} \mathrm{W} \quad 90^{\circ} \mathrm{W} \quad 60^{\circ} \mathrm{W} \quad 30^{\circ} \mathrm{W} \quad 0$

Longitude

Figure 19: Annual mean sea surface temperature (K) anomaly for HCSA poleward expansion cases in the period 1996-2011 based on the HADISST dataset. Contour intervals are $0.1 \mathrm{~K}$ with stippling indicating regions statistically significant above the $95 \%$ confidence level as determined by two-tailed Student's $t$-test.

expansion cases is weaker compared to the intensification cases, probably associated with reduced temperature anomalies over northern SA (Figure 17(a)); however, the descending branch is stronger and shifted poleward, as expected (Figures 3(a) and 3(b)). The ascending branch of the Walker circulation for HCSA poleward expansion cases over the northern SA (around $70^{\circ} \mathrm{W}$ ) is also weaker compared to the strong cases; however, the anomalous upward motion seen along the Atlantic basin is stronger (Figures 12(b) and 12(c)), due to the southward extension of the positive SST anomalies (Figures 11 and 19). This southward extension is associated with the weakening of the trade winds on the equator (Figures 14(b) and 14(d)), in contrast to their intensification in the HCSA strong cases (Figure 6(b)).

The annual anomalous rainfall distribution, during the HCSA poleward expansion cases analyzed (Figure 20) is similar to that seen for strong cases (Figure 13). However, it follows more closely the La Niña canonical impacts, due to the influence of the southward extension of the positive SST anomalies in Atlantic, especially over the edge of northeast SA (mostly positive rainfall anomalies) (Figure 20(a)). Chen et al. [6] found that when the poleward edge of the regional $\mathrm{HC}$ is located to the south of its climatological location, significant descending motion and negative precipitation anomalies can be observed over the regions to the south of the respective regional $\mathrm{HC}$ climatological poleward edge. The significant descending motion around $35^{\circ} \mathrm{S}$ can be seen in Figure 3(b) and the negative precipitation anomalies associated are observed over southeast (south of Brazil, Uruguay, and Argentina) and southwestern coast of SA (from $35^{\circ}$ to $45^{\circ} \mathrm{S}$ ) in Figure 20. The model overestimates the negative rainfall anomalies over south of Brazil and southwestern coast of SA (from $33^{\circ}$ to $45^{\circ} \mathrm{S}$ ). However, Table 5 shows that the highest spatial correlation between the model and observation is found in the southeast of SA. In the northeast SA (region 6 of Figure 5), the observed rainfall anomalies are underestimated by the model (bias $=-0.14$ ), as seen for 


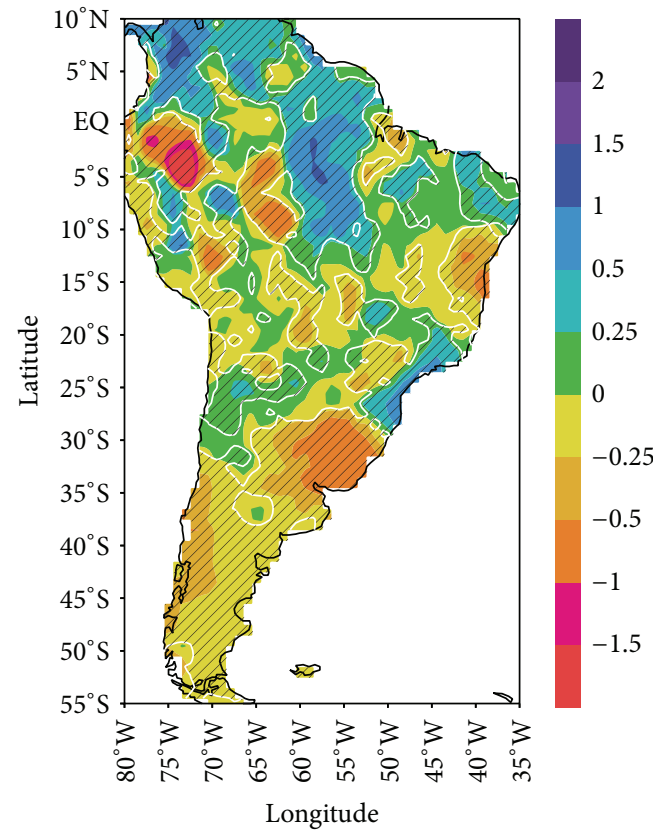

(a)

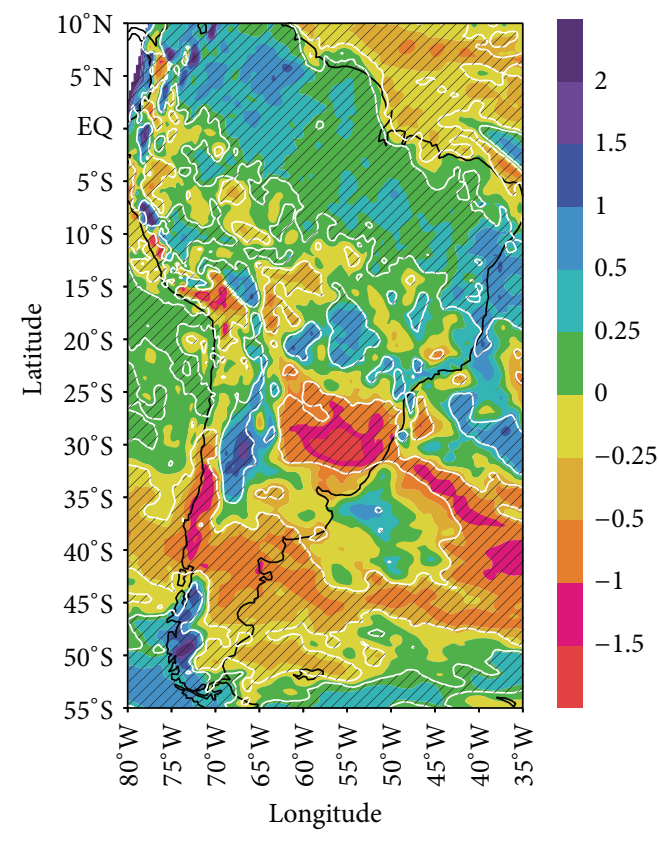

(b)

Figure 20: Precipitation anomaly $\left(\mathrm{mm} \mathrm{day}^{-1}\right.$ ) for HCSA poleward expansion cases in the period 1996-2011 based on the (a) GPCC dataset and (b) RegCM4 simulation. Contour intervals are $0.25 \mathrm{~mm} \mathrm{day}^{-1}$ with hatching indicating regions statistically significant above the $95 \%$ confidence level as determined by two-tailed Student's $t$-test.

TABLE 5: Area averaged root mean square error (RMSE) and bias and spatial correlation coefficient (CC) for the annual mean precipitation $\left(\mathrm{mm} \mathrm{day}^{-1}\right)$ anomalies for HCSA poleward expansion cases over the last three regions of Figure 5 in the period 1996-2011.

\begin{tabular}{lccc}
\hline Region & RMSE $\left(\mathrm{mm} \mathrm{day}^{-1}\right)$ & BIAS $\left(\mathrm{mm} \mathrm{day}^{-1}\right)$ & $\mathrm{CC}$ \\
\hline 5 & 0.47 & 0.06 & 0.65 \\
6 & 0.32 & -0.14 & 0.19 \\
7 & 0.50 & 0.05 & 0.26 \\
\hline
\end{tabular}

the HCSA strong cases. As well, in this region is found the lowest correlation between the model and observation.

Several studies found that the performance of the regional climate models varies regionally and there is no single parameter setting that performs best in all domains tested $[11,39]$. Therefore, the models must be adequately tuned in order to give reliable predictions in the different regions of SA [39]. In both cases (intensification and poleward expansion of the HCSA), the best combination of low values for RMSE and bias (absolute value) and high values for spatial correlation are found in the southern region for the anomalies of zonal wind, geopotential height, and temperature. The precipitation anomalies were reasonably reproduced by the model in the southeast region. This indicates that the southern SA exhibits good agreement between the model and observations. Therefore, the current model setup is considered satisfactory for application in future climate studies in this region.

\section{Discussion and Conclusions}

This paper investigated the impacts of changes in the intensity and poleward edge of regional $\mathrm{HC}$ over SA on the patterns of wind, geopotential height, precipitation, and temperature using the regional climate model (RegCM4) and observational datasets during the 1996-2011 period.

Several studies indicate a weakening and poleward expansion of the zonal HC in a global warming scenario [4, 41]. However, the changes in the regional $\mathrm{HC}$ can be different and they are still lesser known. As well, zonally averaged changes may reflect strong regional circulation changes.

Our results have shown that, during the 1996-2011 period, there are trends of intensification and poleward expansion of the HCSA. Therefore, composites were constructed to evaluate the impacts of these changes in the HCSA on the patterns of wind, geopotential height, precipitation, and temperature. Significant correlations are seen between the temperature, zonal wind, and the HCSA intensity over the northern, central, and southern regions of SA and South Atlantic. Results have also shown that, in both composites, regions with anomalous easterly (westerly) winds coming from (towards) the Atlantic Ocean have negative (positive) correlations with the HCSA intensity and poleward edge.

In summary, the following outcomes have been seen for the HCSA strong cases analyzed:

(i) A cold trough in the central regions of SA and South Atlantic and a warm ridge over the southern SA and South Atlantic around $50^{\circ} \mathrm{S}$. 
(ii) An intense ascending branch of the Hadley and Walker circulations, due to Amazon heat source intensification.

(iii) A La Niña pattern in the equatorial Pacific region and a "new-type" Atlantic Niño with positive SST anomalies centered at $15^{\circ} \mathrm{N}$ due to the weakening of the northern trade winds and strengthening of the trade winds on the equator.

(iv) Annual anomalous rainfall distribution following approximately the La Niña canonical impacts, but also presenting the influence of the positive SST anomalies in Atlantic, especially over the edge of northeast SA (mostly negative rainfall anomalies).

The following outcomes have been seen for the HCSA poleward expansion cases compared to the strong cases analyzed:

(i) A stronger cold trough in the central regions of SA and South Atlantic and a stronger warm ridge over the southern SA and South Atlantic around $50^{\circ} \mathrm{S}$.

(ii) A weaker ascending branch and a stronger and shifted poleward descending branch of the HCSA.

(iii) A weaker ascending branch over the northern SA and an anomalous upward motion seen along the Atlantic basin for the Walker circulation.

(iv) A stronger La Niña pattern in the equatorial Pacific region and a southward extension of the positive SST anomalies in the Atlantic due to weaker trade winds on the equator.

(v) Annual anomalous rainfall distribution following more closely the La Niña canonical impacts due to the influence of the southward extension of the positive SST anomalies in Atlantic, especially over the edge of northeast SA (mostly positive rainfall anomalies).

The performance of the RegCM4 in simulating the climate anomalies over different regions of SA, associated with changes in the HCSA, was assessed. The results have shown that, in general, the model is capable of simulating the main features of the circulation anomalies associated with the intensification and poleward expansion of the HCSA. The performance of the model varies regionally and the southern SA exhibited better agreement between the model and observations for the anomalies of zonal wind, geopotential height, and temperature in the 1996-2011 period. The precipitation anomalies were reasonably reproduced by the model in the southeast region. Studies have shown that the regional climate models show a significant sensitivity to different parameterizations and parameter settings, which can be used to optimize the model performance over different regions. Thus, further studies using other cumulus parametrization, different domain size, and period of simulations will be pursued in the future.

It is important to highlight that the composites representing the HCSA intensification and poleward expansion are different by only one year. This is why notable similarity is found in the results for the intensification and poleward expansion cases, which could indicate that, in most circumstances, the changes in the intensity and poleward edge of the HCSA are occurring simultaneously.

The main differences between the results for the intensification and poleward expansion cases are seen in the statistically significant regions and/or anomalies intensity. The changes in the SST anomalies between the cases help to explain these differences. However, it is always important to have in mind that many mechanisms and interactions can be responsible for controlling the intensity and poleward edge of the regional $\mathrm{HC}$. This is an issue of continually growing knowledge due to complexity of the coupled oceanatmosphere-land system. We hope that this paper contributes to a better understanding about the local impacts of the changes in regional $\mathrm{HC}$ and helps to develop insights into the mechanisms that lead to these spatially heterogeneous changes and into the future of this circulation in a changing climate.

\section{Conflict of Interests}

The authors declare that there is no conflict of interests regarding the publication of this paper.

\section{Acknowledgments}

The authors thank FAPESP (Fundação de Amparo à Pesquisa do Estado de São Paulo) for financial support (Grants 2011/ 13669-0 and 2008/58101-9) for the development of this research. CNPQ (Conselho Nacional de Desenvolvimento Científico e Tecnológico) and ITV (Vale Institute of Technology) have also partially funded Tércio Ambrizzi.

\section{References}

[1] S. Hastenrath, Climate and Circulation of the Tropics, D. Riedel, Dordrecht, The Netherlands, 1985.

[2] C. M. Johanson and Q. Fu, "Hadley cell widening: model simulations versus observations," Journal of Climate, vol. 22, no. 10, pp. 2713-2725, 2009.

[3] J. Lu, G. A. Vecchi, and T. Reichler, "Expansion of the Hadley cell under global warming," Geophysical Research Letters, vol. 34, Article ID L06805, 2007.

[4] D. M. W. Frierson, J. Lu, and G. Chen, "Width of the Hadley cell in simple and comprehensive general circulation models," Geophysical Research Letters, vol. 34, Article ID L18804, 2007.

[5] X. Quan, H. F. Diaz, and M. P. Hoerling, "Change in the tropical Hadley cell since 1950," in The Hadley Circulation: Present, Past and Future, H. F. Diaz and R. S. Bradley, Eds., vol. 21 of Advances in Global Change Research, pp. 85-120, Springer, Dordrecht, The Netherlands, 2004.

[6] S. Chen, K. Wei, W. Chen, and L. Song, "Regional changes in the annual mean Hadley circulation in recent decades," Journal of Geophysical Research: Atmospheres, vol. 119, no. 13, pp. 78157832, 2014

[7] A. H. Oort and J. J. Yienger, "Observed interannual variability in the Hadley circulation and its connection to ENSO," Journal of Climate, vol. 9, no. 11, pp. 2751-2767, 1996.

[8] C. Wang, "ENSO, Atlantic climate variability, and the Walker and Hadley circulations," in The Hadley Circulation: Present, 
Past and Future, H. F. Diaz and R. S. Bradley, Eds., pp. 173-202, Kluwer Academic, 2005.

[9] T. Ambrizzi, E. B. de Souza, and R. S. Pulwarty, "The Hadley and Walker regional circulations and associated ENSO impacts on South American seasonal rainfall," in The Hadley Circulation: Present, Past and Future, H. F. Diaz and R. S. Bradley, Eds., vol. 21 of Advances in Global Change Research, pp. 203-235, Kluwer Academic, New York, NY, USA, 2004.

[10] G. Zeng, W.-C. Wang, Z. B. Sun, and Z. X. Li, "Atmospheric circulation cells associated with anomalous east Asian winter monsoon," Advances in Atmospheric Sciences, vol. 28, no. 4, pp. 913-926, 2011.

[11] F. Giorgi, E. Coppola, F. Solmon et al., "RegCM4: model description and preliminary tests over multiple CORDEX domains," Climate Research, vol. 52, no. 1, pp. 7-29, 2012.

[12] D. P. Dee, S. M. Uppala, A. J. Simmons et al., "The ERA-Interim reanalysis: configuration and performance of the data assimilation system," Quarterly Journal of the Royal Meteorological Society, vol. 137, no. 656, pp. 553-597, 2011.

[13] J. S. Pal, F. Giorgi, X. Bi et al., "Regional climate modeling for the developing world: the ICTP RegCM3 and RegCNET," Bulletin of the American Meteorological Society, vol. 88, no. 9, pp. 13951409, 2007.

[14] J. T. Kiehl, J. J. Hack, G. B. Bonan et al., "Description of the NCAR community climate model (CCM3)," NCAR Technical Note NCAR/TN-420+STR, National Center for Atmospheric Research, Boulder, Colo, USA, 1996.

[15] R. E. Dickinson, A. Henderson-Sellers, and P. Kennedy, "Biosphere-atmosphere transfer scheme (BATS) Version le as coupled to the NCAR community climate model," Technical Report, National Center for Atmospheric Research Technical Note TN-387+STR, NCAR, Boulder, Colo, USA, 1993.

[16] R. A. Anthes, "A cumulus parameterization scheme utilizing a one-dimensional cloud model," Monthly Weather Review, vol. 105, no. 3, pp. 270-286, 1977.

[17] R. Anthes, E.-Y. Hsie, and Y.-H. Kuo, "Description of the Penn State/NCAR Mesoscale model: version 4 (MM4)," NCAR Techical Note NCAR/TN-282+STR, University Corporation for Atmospheric Research, Boulder, Colo, USA, 1987.

[18] G. A. Grell, "Prognostic evaluation of assumptions used by cumulus parameterizations," Monthly Weather Review, vol. 121, no. 3, pp. 764-787, 1993.

[19] F. Giorgi, M. R. Marinucci, G. T. Bates, and G. de Canio, "Development of a second-generation regional climate model (RegCM2). Part II: convective processes and assimilation of lateral boundary conditions," Monthly Weather Review, vol. 121, no. 10, pp. 2814-2832, 1993.

[20] K. A. Emanuel, "A scheme for representing cumulus convection in large-scale models," Journal of the Atmospheric Sciences, vol. 48, no. 21, pp. 2313-2335, 1991.

[21] R. W. Reynolds, N. A. Rayner, T. M. Smith, D. C. Stokes, and W. Wang, "An improved in situ and satellite SST analysis for climate," Journal of Climate, vol. 15, no. 13, pp. 1609-1625, 2002.

[22] M. S. Reboita, L. M. M. Dutra, and R. P. da Rocha, "RegCM4 dynamical downscaling of seasonal climate predictions over the Southeast of Brazil," in Geophysical Research Abstracts, vol. 15, EGU2013-6061, 2013.

[23] M. P. Marcella and E. A. B. Eltahir, "Modeling the summertime climate of Southwest Asia: the role of land surface processes in shaping the climate of semiarid regions," Journal of Climate, vol. 25, no. 2, pp. 704-719, 2012.
[24] U. Schneider, A. Becker, P. Finger, A. Meyer-Christoffer, M. Ziese, and B. Rudolf, "GPCC's new land surface precipitation climatology based on quality-controlled in situ data and its role in quantifying the global water cycle," Theoretical and Applied Climatology, vol. 115, no. 1-2, pp. 15-40, 2014.

[25] N. A. Rayner, D. E. Parker, E. B. Horton et al., "Global analyses of sea surface temperature, sea ice, and night marine air temperature since the late nineteenth century," Journal of Geophysical Research, vol. 108, no. 14, pp. 1-37, 2003.

[26] T. N. Krishnamurti, "Tropical east-west circulations during the northern summer," Journal of the Atmospheric Sciences, vol. 28, no. 8, pp. 1342-1347, 1971.

[27] T. N. Krishnamurti, M. Kanamitsu, W. J. Koss, and J. D. Lee, "Tropical east-west circulations during the northern winter," Journal of the Atmospheric Sciences, vol. 30, no. 5, pp. 780-787, 1973.

[28] S. Hastenrath, "In search of zonal circulations in the equatorial atlantic sector from the NCEP-NCAR reanalysis," International Journal of Climatology, vol. 21, no. 1, pp. 37-47, 2001.

[29] B. Liebmann and C. A. Smith, "Description of a complete (interpolated) outgoing longwave radiation dataset," Bulletin of the American Meteorological Society, vol. 77, pp. 1275-1277, 1996.

[30] K. E. Trenberth, R. Dole, Y. Xue et al., "Atmospheric reanalyses: a major resource for ocean product development and modeling," in Proceedings of the Sustained Ocean Observations and Information for Society (OceanObs '09), J. Hall, D. E. Harrison, and D. Stammer, Eds., vol. 2 of WPP-306, pp. 21-25, ESA Publication, Venice, Italy, September 2009.

[31] R. Lin, T. Zhou, and Y. Qian, "Evaluation of global monsoon precipitation changes based on five reanalysis datasets," Journal of Climate, vol. 27, no. 3, pp. 1271-1289, 2014.

[32] E. Jakobson, T. Vihma, T. Palo, L. Jakobson, H. Keernik, and J. Jaagus, "Validation of atmospheric reanalyses over the central Arctic Ocean," Geophysical Research Letters, vol. 39, no. 10, Article ID L10802, 2012.

[33] M. B. Sylla, E. Coppola, L. Mariotti et al., "Multiyear simulation of the African climate using a regional climate model (RegCM3) with the high resolution ERA-interim reanalysis," Climate Dynamics, vol. 35, no. 1, pp. 231-247, 2010.

[34] J.-H. Park, S. G. Oh, M. S. Suh, and H. S. Kang, "Impact of boundary conditions on RegCM4 20-year-long precipitation simulations over CORDEX-East Asia domain," in Proceedings of the EGU General Assembly, p. 4475, Vienna, Austria, April 2012.

[35] R. J. Bombardi, L. M. V. Carvalho, and C. Jones, "Simulating the influence of the South Atlantic dipole on the South Atlantic convergence zone during neutral ENSO," Theoretical and Applied Climatology, vol. 118, no. 1-2, pp. 251-269, 2014.

[36] F. Cabré, S. Solman, and M. Núñez, "Climate downscaling over southern South America for present-day climate (19701989) using the MM5 model. Mean, interannual variability and internal variability," Atmósfera, vol. 27, no. 2, pp. 117-140, 2014.

[37] I. Richter, S. K. Behera, Y. Masumoto, B. Taguchi, H. Sasaki, and T. Yamagata, "Multiple causes of interannual sea surface temperature variability in the equatorial Atlantic Ocean," Nature Geoscience, vol. 6, no. 1, pp. 43-47, 2013.

[38] C. F. Ropelewski and M. S. Halpert, "Global and regional scale precipitation patterns associated with the El Niño/Southern Oscillation," Monthly Weather Review, vol. 115, no. 8, pp. 16061626, 1987.

[39] J. P. R. Fernandez, S. H. Franchito, and V. B. Rao, "Simulation of the summer circulation over South America by two regional 
climate models. Part I: mean climatology," Theoretical and Applied Climatology, vol. 86, no. 1-4, pp. 247-260, 2006.

[40] M. Rojas, "Multiply nested regional climate simulation for southern South America: sensitivity to model resolution," Monthly Weather Review, vol. 134, no. 8, pp. 2208-2223, 2006.

[41] J. Lu, G. Chen, and D. M. W. Frierson, "Response of the zonal mean atmospheric circulation to El Niño versus global warming," Journal of Climate, vol. 21, no. 22, pp. 5835-5851, 2008.

[42] J. S. Pal, E. E. Small, and E. A. B. Eltahir, "Simulation of regionalscale water and energy budgets: representation of subgrid cloud and precipitation processes within RegCM," Journal of Geophysical Research D: Atmospheres, vol. 105, no. 24, pp. 29579-29594, 2000.

[43] A. A. M. Holtslag, E. I. F. De Bruijn, and H.-L. Pan, "A high resolution air mass transformation model for short-range weather forecasting," Monthly Weather Review, vol. 118, no. 8, pp. 1561-1575, 1990.

[44] X. Zeng, M. Zhao, and R. E. Dickinson, "Intercomparison of bulk aerodynamic algorithms for the computation of sea surface fluxes using TOGA COARE and TAO data," Journal of Climate, vol. 11, no. 10, pp. 2628-2644, 1998. 

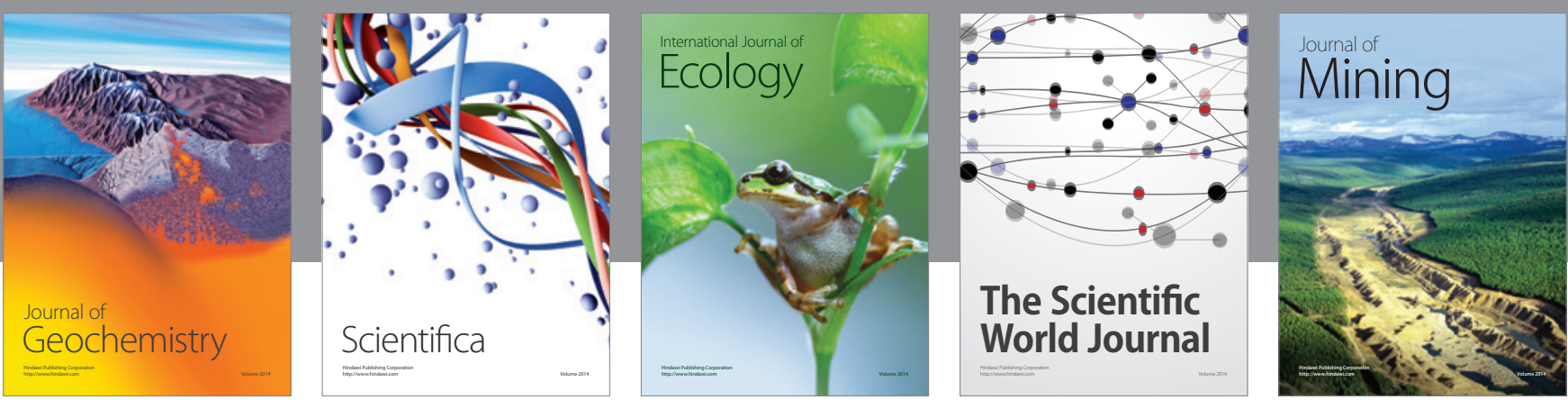

The Scientific World Journal
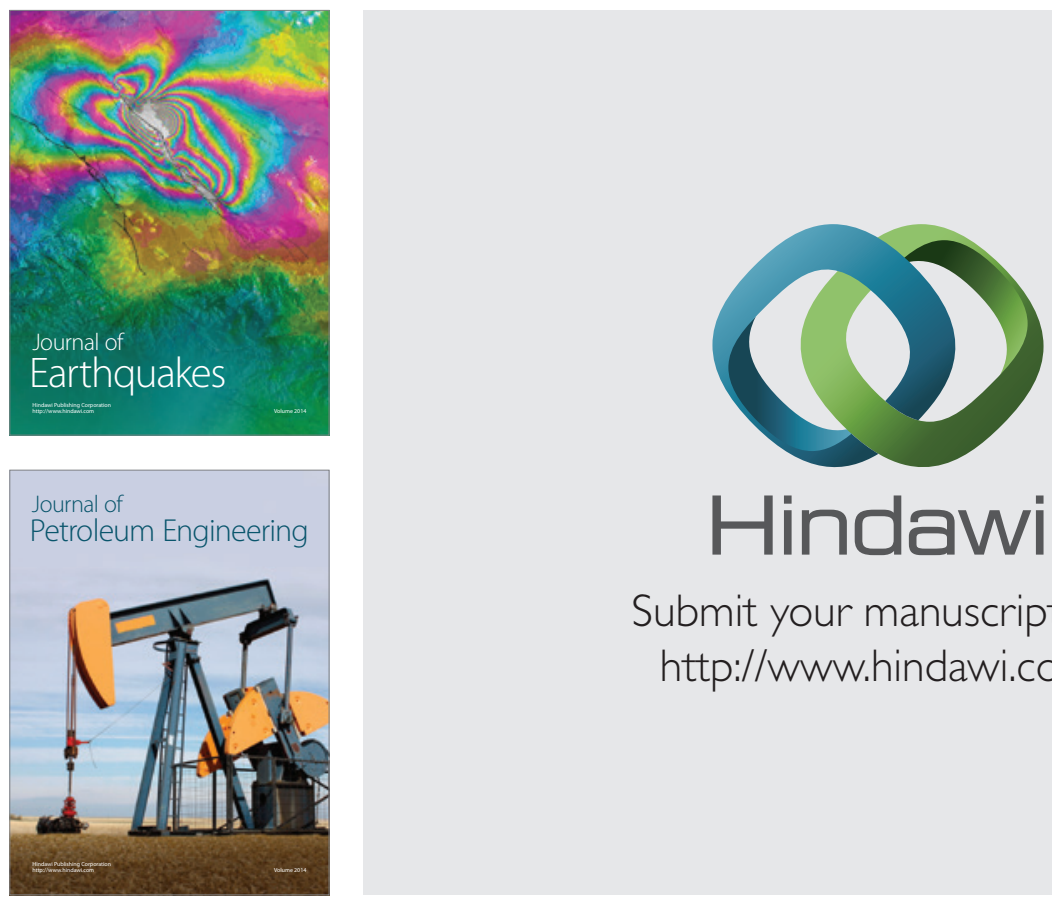

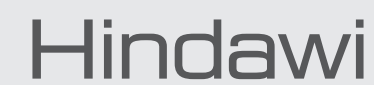

Submit your manuscripts at

http://www.hindawi.com
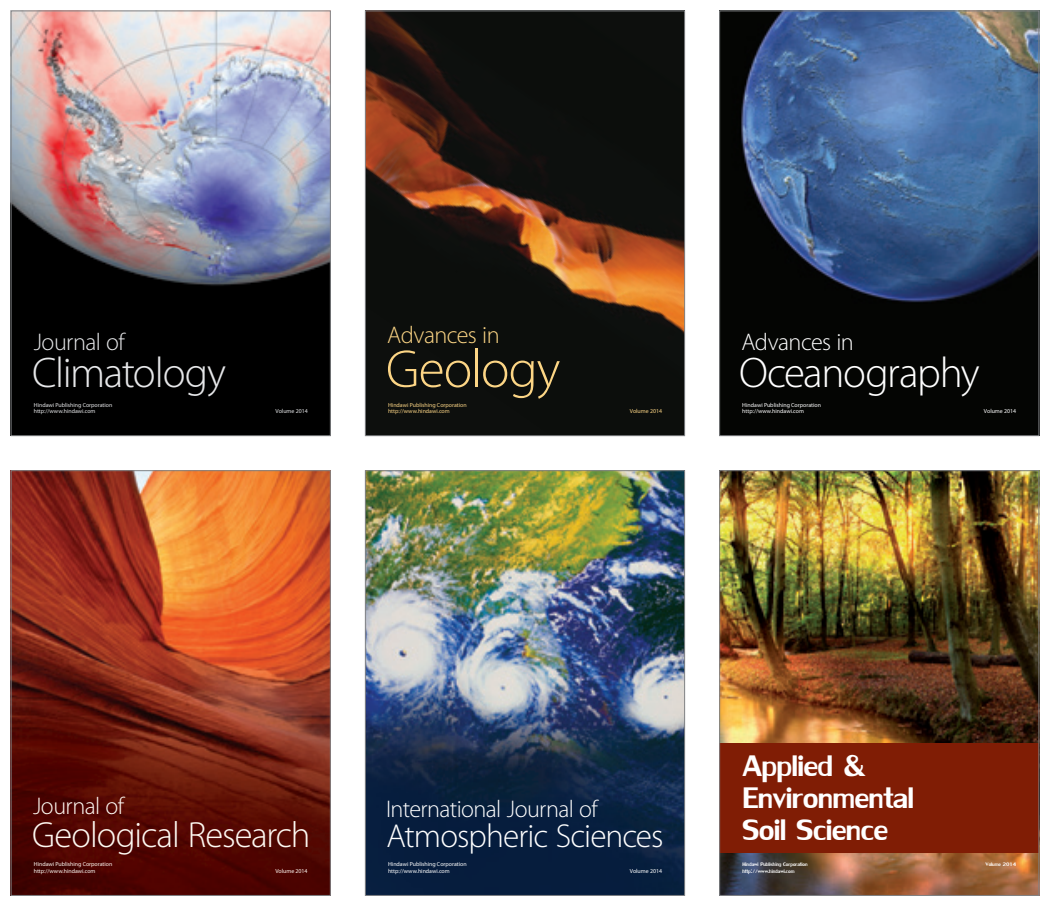
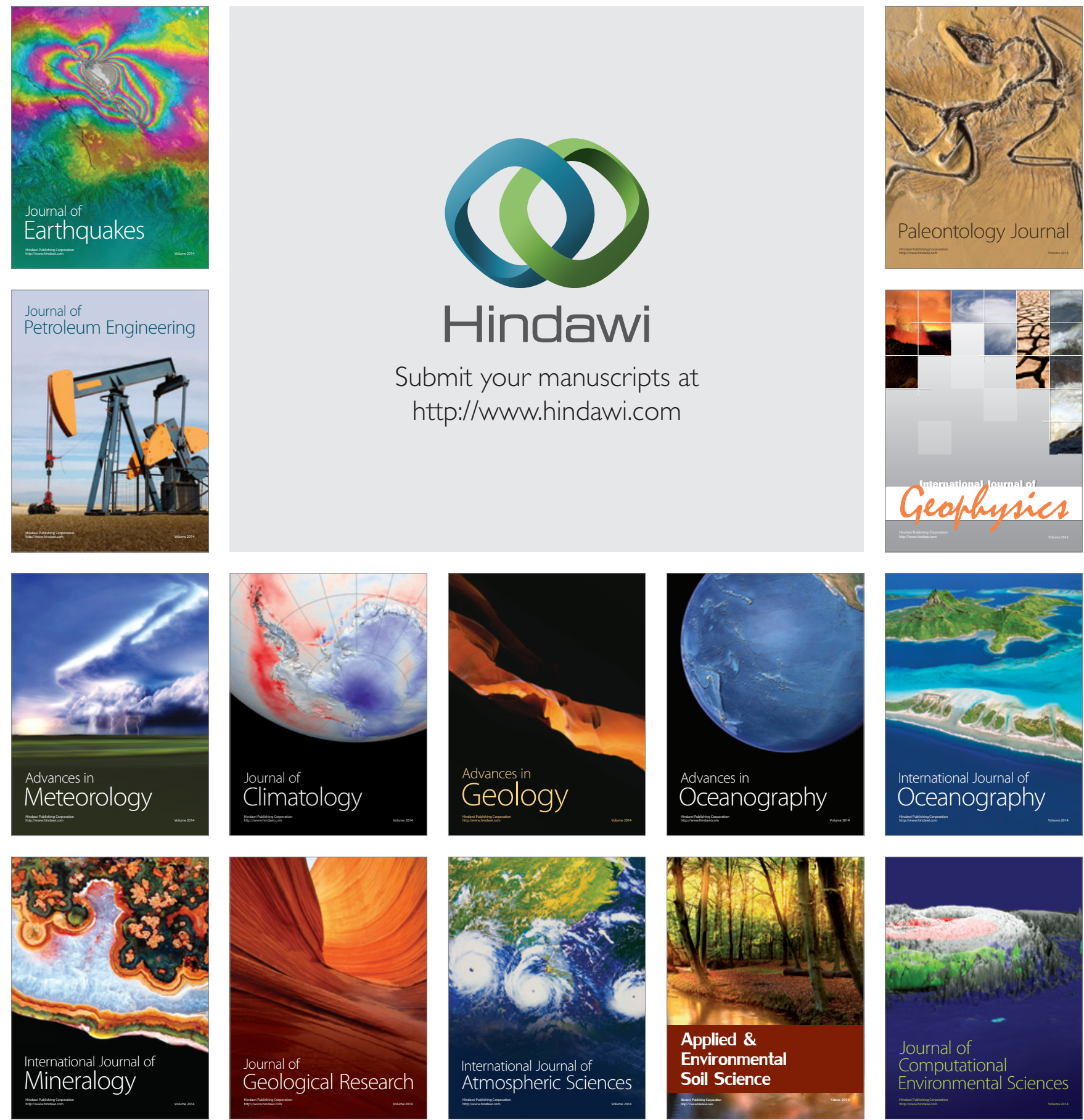